Revista de Estudios Histórico-Jurídicos

[Sección derecho romano]

XLIII (Valparaíso, Chile, 2021)

[pp. 135-161]

\title{
Aliud EST ENIM CREDERE, ALIUd DEPONERE. Sobre LA RELACIÓN ENTRE CAUSAS CREDITICIAS Y DEPÓSITO EN EL PENSAMIENTO DE ULPIANO
}

[Aliud est enim credere, aliud deponere. On the Relationship between Credit Causes and Deposit in the Thought of Ulpian]

\author{
Adolfo Wegmann Stockebrand* \\ Pontificia Universidad Católica de Chile
}

\begin{abstract}
RESUMEN
El presente artículo tiene por objeto analizar el tratamiento del problema de la relación entre las causas crediticias y el depósito en el pensamiento de Ulpiano, el que pareciera estar sintetizado en el dictum ulpianeo aliud est enim credere, aliud deponere. Se intenta demostrar que los fragmentos ulpianeos estudiados parten siempre de la base de consideraciones centradas en la estructura funcional del deponere, a fin de distinguirlo del credere, ya sea omitiendo toda referencia al depositum en su explicación del contenido del edictum de rebus creditis $(12,1,1,1)$, o bien, contraponiendo explícitamente ambas nociones en el contexto de las acreencias privilegiadas contra un banquero insolvente (D. 42,5,24,2). Dicha postura contrasta con la de otros ju-
\end{abstract}

\begin{abstract}
The purpose of this article is to analyze the treatment of the problem of the relationship between credit causes and the deposit in Ulpian's thought, which seems to be synthesized in the dictum aliud est enim credere, aliud deponere. An attempt is made to demonstrate that the ulpianean fragments studied are always based on considerations focused on the functional structure of the deponere, in order to distinguish it from the credere, either by omitting any reference to the depositum in their explanation of the content of the edictum de rebus creditis $(12,1,1,1)$, or explicitly contrasting both notions in the context of privileged claims against an insolvent banker (D. $42,5,24,2)$. This position contrasts with that of other classical jurists such as Gaius
\end{abstract}

* Doctor en Derecho, Universidad de Heidelberg, Alemania. Profesor de derecho civil y derecho romano en la Pontificia Universidad Católica de Chile. Dirección postal: Avenida Libertador Bernardo O’Higgins 340, Santiago, Chile. Correo electrónico: aawegman@uc.cl. Este artículo forma parte del proyecto Fondecyt de Iniciación en Investigación N 11170478 “Aliud est enim credere, aliud deponere. Sobre la relación entre causas crediticias y depósito en el derecho romano clásico", del cual el autor es investigador responsable. ORCID 0000-0001-8741-2099. 
ristas clásicos como Gayo y Paulo, quienes se muestran más atentos a las semejanzas procesales entre deponere y credere, motivo por el cual es posible encontrar en sus obras un tratamiento más bien ambiguo y asistemático de la cuestión, donde pareciera no haber una real incompatibilidad entre ambas categorías.

Palabras clave

Credere - deponere - condictio - edictum de rebus creditis. and Paul, who are more attentive to the procedural similarities between deponere and credere, which is why it is possible to find in their works a rather ambiguous and unsystematic treatment of the issue, where there seems to be no real incompatibility between the two categories.

KEY WORDS
Credere - deponere - condictio - edictum
de rebus creditis.

RECIBIDO el 16 de octubre de 2020 y ACEPTADO el 21 de abril de 2021

\section{INTRODUCCIÓN ${ }^{1}$}

El presente artículo aborda el problema de la aparente exclusión del depósito de la categoría de las causas crediticias en el pensamiento de Ulpiano, según se sintetiza en el dictum ulpianeo aliud est enim credere, aliud deponere. Lo anterior, a pesar de que el depósito, tanto en su estructura negocial (aspecto, por así decirlo, material) como en lo concerniente a su accionabilidad (aspecto, por así decirlo, procesal), presenta evidentes semejanzas con figuras como el comodato y la prenda, que nacen de la entrega no translaticia de dominio sobre una cosa (traditio en sentido lato) y están protegidas por acciones estrictamente restitutorias incluidas en el edictum de rebus creditis y que, en cuanto tales, se insertan sin duda en la categoría de las causae credendi, según se desprende del testimonio del propio Ulpiano al comentar dicho título edictal.

En concreto, buscamos demostrar que la compleja relación entre credere y deponere en época clásica se debió a la interacción de criterios tanto procesales como materiales, las cuales no siempre contaron con una calificación unívoca en el seno de la jurisprudencia romana. Así, mientras Ulpiano -siguiendo probablemente a Celso- parece excluir el deponere de la categoría del credere, ya sea omitiendo toda referencia al depósito en el marco de su exposición del contenido del edictum de rebus creditis (D. 12,1,1,1) ${ }^{2}$, o bien, contraponiendo explícitamente

\footnotetext{
${ }^{1}$ Lista de abreviaturas: $A G .=$ Archivio Giuridico 'Filippo Serafini'; $A H D E .=$ Anuario de Historia del Derecho Español; $A U P A$. = Annali del Seminario Giuridico dell'Università di Palermo; BIDR. = Bullettino dell'Istituto di Diritto Romano 'Vittorio Scialoja'; ED. = Enciclopedia del Diritto; Index = Index. Quaderni camerti di studi romanistici; Iura = Iura: Rivista Internazionale di Diritto Romano e Antico; Labeo = Labeo. Rassegna di diritto romano; RChD. $=$ Revista Chilena de Derecho; REHJ. = Revista de Estudios Histórico-Jurídicos; RIDA. = Revue internationale des droits de l'antiquité; SCDR. = Seminarios Complutenses de Derecho Romano; SDHI. $=$ Studia et Documenta Historiae et Iuris; TR. $=$ Tijdschrift voor Rechtsgeschiedenis; ZSS. = Zeitschrift der Savigny-Stiftung für Rechtsgeschichte (romanistische Abteilung).

${ }^{2}$ Exégesis de la fuente infra, II.
} 
ambas nociones (D. $42,5,24,2)^{3}$, otros juristas se muestran más ambiguos en el tratamiento de la cuestión.

En efecto, como hemos señalado en un trabajo precedente, se advierte en Paulo (un contemporáneo de Ulpiano) cierta tendencia a un acercamiento entre credere y deponere desde la perspectiva de su accionabilidad, al reconocer al depositante la legitimación para ejercer la condictio (acción paradigmática del credere edictal) contra el depositario que non reddit, sin que sea necesario que se configure un supuesto de furtum, toda vez que la infitiatio del depositario (entendida aquí como negativa dolosa a restituir) no representa de suyo una hipótesis de contrectatio ${ }^{4}$; lo cual, a los ojos del jurista, pareciera no ser incompatible con la estructura del título edictal de rebus creditis (D. 12,1,2pr. y 3$)^{5}$.

Otro tanto puede decirse del autor de las res cottidianae (para nosotros, Gayo) ${ }^{6}$, el cual, en una primera aproximación a la fuente ${ }^{7}$, pareciera querer extender el sentido y alcance del re contrahere (limitado en el derecho romano clásico al solo mutuum, como hemos intentado demostrar anteriormente $)^{8}$ al comodato, el depósito y

${ }^{3}$ Exégesis de la fuente infra, III.

${ }^{4}$ Así se desprende del propio Paulo en D. 47,2pr.-3 (Paul. 39 ad ed.): "Furtum a furvo, id est nigro dictum Labeo ait, quod clam et obscuro fiat et plerumque nocte: vel a fraude, ut Sabinus ait: vel a ferendo et auferendo: vel a Graeco sermone, qui fwras appellant fures: immo et Graeci apo tou ferein fwras dixerunt. 1. Inde sola cogitatio furti faciendi non facit furem. 2. Sic is, qui depositum abnegat, non statim etiam furti tenetur, sed ita, si id intercipiendi causa occultaverit. 3. Furtum est contrectatio rei frandulosa lucri faciendi gratia vel ipsius rei vel etiam usus eius possessionisve, quod lege naturali probibitum est admittere"; D. 41,2,3,18 (Paul. 54 ad ed.): "Si rem apud te depositam furti faciendi causa contrectaveris, desino possidere. Sed si eam loco non moveris et infitiandi animum habeas, plerique veterum et Sabinus et Cassius recte responderunt possessorem me manere, quia furtum sine contrectatione fieri non potest nec animo furtum admittatur". Cfr. la opinión de Celso en D. 47,2,68pr. (Cels. 12 dig.): "Infitiando depositum nemo facit furtum (nec enim furtum est ipsa infitiatio, licet prope furtum est): sed si possessionem eius apiscatur intervertendi causa, facit furtum. nec refert, in digito habeat anulum an dactyliotheca quem, cum deposito teneret, habere pro suo destinaverit'. Sobre el carácter no necesariamente furtivo del non reddere véase recientemente PENNITZ, Martin, Das 'non reddere' als Deliktstatbestand - Juristendiskurse zu Besitz, Detention und Diebstabl, en Index, 46 (Napoli, 2018), pp. 201 ss.

${ }^{5}$ D. 16,3,13,1 (Paul. 31 ad ed.): "Competit etiam condictio depositae rei nomine, sed non antequam id dolo admissum sit: non enim quemquam hoc ipso, quod depositum accipiat, condictione obligari, verum quod dolum malum admiserit'. Véase también D. 12,1,2pr. y 3 (Paul. 28 ad ed.). Para una exégesis detallada de estos fragmentos nos remitimos a Wegmann STOckebrand, Adolfo, ¿Ex causa depositi condicere? Observaciones sobre credere y deponere en el pensamiento de Paulo, en REHJ., 42 (Valparaíso, 2020), pp. 193 ss., con amplia bibliografía.

${ }^{6}$ En este sentido p.ej. FalCONE, Giuseppe, Sistematiche gaiane e definizione di obligatio, en Capogrossi-Colognesi, Luigi; Cursi, Maria Floriana (eds.), Obligatio-obbligazione. Un confronto interdisciplinare (Atti del Convegno di Roma 23-24 settembre 2010) (Napoli, Jovene, 2011), p. 17; MARTINI, Remo, Gaio e le res cottidianae, en AUPA., 55 (Palermo, 2012), pp. 171 ss. Recientemente sobre la relación entre esta obra y las Gai Institutiones PLATSCHEK, Johannes, Das Verhältnis der Institutiones zu den so genannten Res cottidianae sive aurea, en Babusiaux, Ulrike; Mantovani, Dario (eds.), Le Istituzioni di Gaio: avventure di un bestseller. Trasmissione, uso e trasformazione del testo (Pavia, Pavia University Press, 2020), pp. 279 ss.

${ }^{7}$ D. 44,7,1,2-6 (Gai. 2 aur.): 2. "Re contrabitur obligatio mutui datione". 3. "Is quoque, cui rem aliquam commodamus, re nobis obligatur [...]". 5. "Is quoque, apud quem rem aliquam deponimus, re nobis tenetur $[. .]$.$" . 6. "Creditor quoque, qui pignus accepit, re tenetur [. .$.$] ".$

${ }^{8}$ Wegmann Stockebrand, Adolfo, Obligatio re contracta. Ein Beitrag zur sogenannten Kategorie 
la prenda, mediante un uso amplísimo, atécnico y extremadamente débil de las nociones de re obligari y re tener ${ }^{9}$. Sin embargo, de una exégesis atenta de la fuente se desprende que, con toda probabilidad, de lo que se trata en las res cottidianae es de constatar que tanto el comodato como el depósito y la prenda se asemejan en cierta medida al mutuo en virtud del carácter estrictamente restitutorio de las acciones honorarias destinadas a exigir el simple valor de las cosas entregadas (las actiones commodati, depositi y pigneraticia in factum conceptae, respectivamente), concebidas según el modelo de la condictio ${ }^{10}$ del mutuo, paradigma de las acciones que conforman el edictum de rebus creditis y, con ello, núcleo de la noción clásica de creditum. Luego, mutuo, comodato, depósito y prenda aparecerían tratados unitariamente en las res cottidianae no en cuanto supuestos de obligatio re contracta, sino en virtud de su naturaleza crediticia, vale decir, como causae credendi ${ }^{11}$.

Por consiguiente, nuestro plan de trabajo exige, ante todo, exponer brevemente la evolución histórica de la noción de credere antes de su fijación definitiva en el edicto perpetuo, esto es, el asíllamado credere pre-edictal (I), para luego, sobre esa base, llevar a cabo una exégesis de dos fragmentos que dan cuenta de la exclusión del deponere de la categoría del credere en el pensamiento de Ulpiano, como es el caso de D. 12,1,1,1 (II) y D. 42,5,24,2 (III). Finalmente, se ofrecen conclusiones y perspectivas de investigación (IV).

\section{El Así LLAMAdo CREDERE PRE-EDICTAL}

$\mathrm{Al}$ margen de la incertidumbre en torno a la precisa etimología del vocablo latino credere, con toda probabilidad éste deriva de la reconstruida raíz proto-indoeuropea kred-dhe, estrechamente vinculada a las ideas de confianza y creer $^{12}$. De ahí que por credere haya que entender esencialmente un fidem sequi, lo cual es válido tanto en el campo jurídico como en el estrictamente religioso o moral ${ }^{13}$.

der Realverträge im römischen Recht (Tübingen, Mohr Siebeck, 2017), pp. 115 ss.; ÉL MISMO, Sobre el asi llamado contrato real en las Instituciones de Gayo, en REHJ., 40 (Valparaíso, 2018), pp. 97 ss.

${ }^{9}$ Ya había reparado en este punto WubBe, Felix, I contratti reali alla fine della repubblica, en Milazzo, Francesco (ed.), Contractus e pactum. Tipicità e libertà negoziale nell'esperienæa tardo-repubblicana (Napoli, Edizioni Scientifiche Italiane, 1990), p. 119: "La responsabilità introdotta con le nuove actiones in factum conceptae abituerà i giuristi all'idea che il detentore, siccome sarà debitore ove non restituisca la cosa, ha l'obbligazione contrattuale di restituire. Si tratta di una specie di riflesso [...]. Cosi depositario, comodatario e creditore pignoratizio potrebbero, a partire del momento in cui ricevono la cosa, essere considerati debitori, obligati re in un senso debolissimo di tale espressione". Cfr. ÉL MISMO, Gaius et les contrats réels, en TR., 35 (Leiden, 1967), pp. 500 ss.

${ }^{10}$ De ahí su calificación como kondiktionenartige Klagen. Cfr. PERnICE, Alfred, Labeo. Römisches Privatrecht im ersten Jahrbundert der Kaiserzeit (Halle, 1873, reimp. Aalen, Scientia, 1963), I, pp. 429 ss.; KASER, Max, Quanti ea res est. Studien zur Methode der Litisästimation im klassischen römischen Recht (München, C.H. Beck, 1935), pp. 65 ss.

${ }^{11}$ Wegmann Stockebrand, Adolfo, Causae credendi y obligatio re contracta en las res cottidianae, en REHJ., 41 (Valparaíso, 2019), pp. 87 ss.; ÉL MISMO, Obligatio re contracta, cit. (n. 8), pp. 218 ss.

${ }^{12}$ Cfr. Ernout, Alfred; Meillet, Antoine, Dictionnaire Étymologique de la langue latine. Histoire $\operatorname{des~mots~}^{4}$ (Paris, Klincksieck, 1959), p. 148; WaLdE, Alois; Hofmann, Johann Baptist, Lateinisches Etymologisches Wörterbuch ${ }^{3}$ (Heidelberg, Winter, 1938), I, p. 287.

${ }^{13}$ Cfr. Heumann, Hermann Gottlieb; Seckel, Emil, Handlexikon zu den Quellen des römischen Rechts $^{9}$ (Jena, Fischer, 1926), p. 111. 
En su vertiente jurídica, el núcleo semántico originario de credere se identifica con la dación mutuaria (mutui datio), esto es, con la transferencia de dominio de una cantidad cierta de aquellas cosas que se determinan según su peso, número o medida (res, quae res pondere, numero, mensura constant ${ }^{14}$; en lenguaje moderno: cosas fungibles ${ }^{15}$ ), las que representan las cosas ciertas (certae res) por antonomasia ${ }^{16}$. En efecto, numerosas fuentes que cubren seis siglos de desarrollo jurídico romano, desde la República tardía hasta los tiempos de Justiniano, dan cuenta de la mutui datio como paradigma del credere. ${ }^{17}$ Lo anterior confirmaría la tesis de Pariente, según la cual el verbo credere estaría relacionado con cernere (dividir, separar, distinguir) y dare (dar), de manera que credere implicaría un certum dare, en el sentido de dar una o más cosas ciertas que deben devolverse ${ }^{18}$. En otros términos: el fidem sequi se expresa en la transferencia del dominio sobre un certum (certum dari) con miras a obtener luego la restitución del tantundem eiusdem generis, hipótesis que en el marco del derecho contractual romano se identifica más allá de toda duda con la mutui datio.

En este sentido, vale la pena tener presente el testimonio de Gai. 3,124: "Sed beneficium legis Corneliae omnibus commune est. qua lege idem pro eodem apud eundem eodem anno vetatur in ampliorem summam obligari creditae pecuniae quam in XX milia; et quamvis sponsores vel fidepromissores in amplam pecuniam, velut in sestertium $C$ milia se obligaverint, tamen dumtaxat in XX milia tenentur. pecuniam autem creditam dicimus non solum eam, quam credendi causa damus, sed omnem, quam tum, cum contrabitur obligatio, certum est debitum iri, id est, quae sine ulla condicione deducitur in obligationem; itaque et ea pecunia, quam in diem certum dari stipulamur, eodem numero est, quia certum est eam debitum iri,

${ }^{14}$ Gai. 3,90: "Re contrabitur obligatio velut mutui datione; mutui autem datio proprie in bis fere rebus contingit, quae res pondere, numero, mensura constant [...]”. Cfr. D. 12,1,2,1 (Paul. 28 ad ed.), con sutiles variaciones lingüísticas.

${ }^{15} \mathrm{El}$ término fungible no es propiamente romano, aunque deriva del lenguaje empleado por Paulo en D. 12,1,2,1 (Paul. 28 ad ed.): "[...] quia in genere suo functionem recipiunt per solutionem quam specie [...]”. Un estudio de la categoría de las cosas fungibles en perspectiva diacrónica en RüFnER, Thomas, Vertretbare Sachen? Die Geschichte der res, quae pondere numero mensura constant (Berlin, Duncker \& Humblot, 2000).

${ }^{16}$ Cfr. Albanese, Bernardo, Per la storia del creditum, en AUPA., 32 (Palermo, 1971), pp. 12 ss. Un detallado estudio sobre el origen de la noción romana de certum y su relación con las así llamadas cosas fungibles en VARvaro, Mario, Per la storia del certum. Alle radici della categoria delle cose fungibili (Torino, Giappichelli, 2008), esp. pp. 153 ss.

${ }^{17}$ Véase p.ej. Gai. 3,124; D. 12,1,1,1 (Ulp. 26 ad ed.), fuente en la que centramos nuestro análisis en el siguiente acápite; D. 12,1,2pr.-1 y 3 (Paul. 28 ad ed.); D. 12,1,8 (Pomp. 6 ad Plaut.); D. 12,1,20 (Iul. 18 dig.); D. 12,1,30 (Paul. 5 ad Plaut.); D. 12,1,41 (Afr. 8 quaest.); D. 14,1,7,1 (Afr. 8 quaest.); D. 14,3,19,3 (Pap. 3 resp.); D. 14,6,1pr. (Ulp. 29 ad ed.); D. 16,1,17pr. (Afr. 4 quaest.); D. 17,1,34pr. (Afr. 8 quaest.); D. 17,1,48pr. (Cels. 7 dig.); D. 19,2,31 (Alf. 5 dig. a Paul. epit.); D. 19,5,24 (Afr. 8 quaest.); D. 20,5,12,1 (Tryph. 8 disp.); D. 24,1,50pr. (Iav. 13 epist.); D. 26,7,16 (Paul. 7 ad Sab.); D. 31,85 (Paul. 4 resp.); D. 42,5,24,2 (Ulp. 63 ad ed.); D. 45,1,126,2 (Paul. 3 quaest.).

${ }^{18}$ PARIENTE, Ángel, Sobre la etimología de 'credere', en SDHI., 19 (Città del Vaticano, 1953), pp. 340 ss. Acepta esta etimología D’Ors, Álvaro, Creditum, en AHDE., 33 (Madrid, 1963), pp. 345 ss. Un interesante análisis crítico en Castresana Herrero, Amelia, Reflexión sobre la significación juridica de 'auctoritas', 'credere' y 'pontifex' a propósito de las etimologías de A. Pariente, en BIDR., 91 (Roma, 1988), pp. 427 ss. 
licet post tempus petatur. appellatione autem pecuniae omnes res in ea lege significantur; itaque et si ninum uel frumentum aut si fundum uel hominem stipulemur, haec lex observanda est'.

En este fragmento de las Institutiones, Gayo explica la ampliación que la noción de pecunia credita experimentó como consecuencia de la dictación de la lex Cornelia, aclarando que, a partir de entonces, no solo se llamó dinero dado en crédito el prestado (evidentemente, en mutuo: credendi causa), sino todo el que en el momento de contraerse la obligación, es cierto que será debido:pecuniam autem creditam dicimus non solum eam, quam credendi causa damus, sed omnem, quam tum, cum contrabitur obligatio, certum est debitum iri. Luego, en virtud de esta lex la pecunia credita habría dejado de ser únicamente el dinero dado en mutuo, y habría pasado a identificarse con toda certa pecunia cuya entrega puede exigirse por medio de una actio certae creditae pecuniae, como es el caso del dinero debido por stipulatio (certi) o expensilatio ${ }^{19}$.

La explicación gayana da cuenta, por tanto, de una extensión del sentido y alcance originario -y que todavía coincidiría con el lenguaje común de su tiempodel credere, acaecida a comienzos del siglo I a.C., en tiempos de Sila ${ }^{20}$; lo anterior, probablemente con la finalidad de destacar la cesura que la lex Cornelia significó para la habitual comprensión del vocablo credere en el tráfico jurídico romano. De ahí que no deba extrañar que, algunos decenios después de esta intervención legislativa, Cicerón haya presentado en un alegato judicial una tripartición del certam pecuniam dare oportere y, con ello, del fundamento de la actio certae creditae pecuniae, en mutui datio, stipulatio y expensilatio ${ }^{21}$. Así las cosas, el credere representaría una suerte de Oberbegriff ${ }^{2}$ de los potenciales supuestos de ejercitabilidad de la condictio, sea en su forma de actio certae creditae pecuniae o de condictio certae rei (también llamada triticaria).

Con todo, que el núcleo originario del credere se encuentra constituido por la mutui datio, es un dato incontestable incluso para la jurisprudencia romana tardoclásica, como lo demuestra la insistencia de Paulo en el punto, más de doscientos años después de Sila y Cicerón, y más de cien después de Gayo, en D. 12,1,2,3 (Paul. 28 ad ed.): "Creditum ergo a mutuo differt qua genus a specie: nam creditum consistit extra eas res, quae pondere numero mensura continentur sic, ut, si eandem rem recepturi sumus, creditum est. item mutuum non potest esse, nisi proficiscatur pecunia, creditum autem interdum etiam si nibil proficiscatur, veluti si post nuptias dos promittatur". Aquí, el jurista tardoclásico, en el marco de su comentario al edictum de rebus creditis ${ }^{23}$, afirma que la relación entre creditum y mutuum es la de género y especie, ya que el primero no se reduce a la transferencia de la propiedad sobre un certum con miras a consti-

${ }^{19}$ NeLson, H.L.W.; Manthe, Ulrich, Gai Institutiones III 88-181. Die Kontraktsobligationen. Text und Kommentar (Berlin, Duncker \& Humblot, 1999), p. 184.

${ }^{20}$ Véase por todos Rotond, Giovanni, Leges publicae populi romani. Elenco cronologico con una introdužione sull'attività legislativa dei comizi romani (Milano, Società Editrice Libraria, 1912), p. 362.

${ }^{21}$ Cic., pro Rosc. com. 4,13: "Iam duae partes causae sunt confectae; adnumerasse sese negat, expensum tulisse non dicit, cum tabulas non recitat. Reliquum est ut stipulatum se esse dicat [...]"; 5,14: "Pecunia petita est certa; cum tertia parte sponsio facta est. Haec pecunia necesse est aut data aut expensa lata aut stipulata sit". Cfr. Wegmann Stockebrand, Adolfo, Obligatio re contracta, cit. (n. 8), pp. 43 ss., con bibliografía.

${ }^{22}$ Nelson, H.L.W.; Manthe, Ulrich, Gai Institutiones, cit. (n. 19), p. 184; Kaser, Max, Das Römische Privatrecht ${ }^{2}$ (1959, München, C.H. Beck, 1971), I, p. 525.

${ }^{23}$ Lenel, Otto, Palingenesia Iuris Civilis (Leipzig, ex officina Bernhardi Tauchnitz, 1889), I, cc. 1020 ss. 
tuir una obligación de reddere genérica (tantundem eiusdem generis, como es el caso, precisamente, de la certa pecunia dada en mutuo), sino que también se extiende a la obligación restitutoria de especie o cuerpo cierto (si eandem rem recepturi sumus, creditum est), como ocurre en el comodato y el depósito, negocios que Paulo distingue expresamente del mutuo a este respecto en el principium de la misma fuente: D. 12,1,2pr. (Paul. 28 ad ed.): "Mutuum damus recepturi non eandem speciem quam dedimus (alioquin commodatum erit aut depositum), sed idem genus: nam si aliud genus, veluti ut pro tritico vinum recipiamus, non erit mutuum" 24 . En síntesis: los textos precedentemente analizados son indicios suficientemente sólidos a favor de la identificación del significado jurídico originario del credere con la mutui datio.

Ahora bien, en la jurisprudencia tardorepublicana se advierte una ulterior ampliación del sentido originario de credere en lo que respecta a sus posibles causas (causae credendi): si, por una parte, la transferencia del dominio de certae res sigue siendo un requisito indispensable del creditum, por la otra, se extiende a figuras que, si bien son en cierta medida analogables a la mutui datio, como es el caso de la así llamada locatio conductio irregularis ${ }^{25}$ y el depositum irregulare ${ }^{26}$, no dejan de constituir supuestos conceptualmente distinguibles entre sí. Lo anterior, según se desprende del siguiente fragmento extraído del Epitome de Paulo a los Digesta del auditor serviano Alfeno Varo ${ }^{27}$ : D. 19,2,31 (Alf. 5 dig. a Paulo epit.): "In navem

\footnotetext{
${ }^{24}$ Estimamos que esta fuente, junto a D. 16,3,13,1 (Paul. 31 ad ed.), donde se concede al depositante una condictio (condictio depositae rei nomine) contra el depositario que se niega dolosamente a restituir la res deposita, permite sostener la tesis según la cual, a diferencia de Ulpiano (como veremos en el acápite siguiente), Paulo no distinguió tajantemente entre credere y deponere, sino que bien pudo considerar al depósito como una causa crediticia. Cfr. WeGmann STOCKEBRAND, Adolfo, ¿Ex causa depositi condicere?, cit. (n. 5), pp. 193 ss.

${ }^{25}$ Véase p.ej. Metro, Antonino, Locazione e acquisto della proprietà: la c.d. locatio-conductio 'irregularis', en SCDR., 7 (Madrid, 1995), pp. 191 ss.; BENKE, Nikolaus, Zum Eigentumserwerb des Unternehmers bei der 'locatio conductio irregularis', en ZSS., 104 (Graz, 1987), pp. 156 ss.; Brasiello, Ugo, Il cosi detto deposito irregolare e la c. d. locatio operis irregolare, en Problemi di diritto romano esegeticamente valutati (Bologna, Pàtron, 1954), I, pp. 23 ss.

${ }^{26}$ Aunque esta denominación no es clásica, sino que tiene un origen bizantino (se califica el

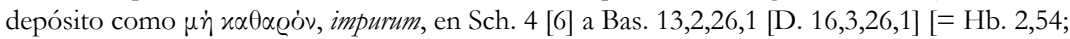
Sch. B2, 663]), sí lo es el tratamiento del problema del depósito de cosas fungibles, en particular de dinero, y su relación con el mutuo. Véase p.ej. D. 12,1,9,9 (Ulp. 26 ad ed.); D. 12,1,10 (Ulp. 2 ad ed.); D. 16,3,1,34 (Ulp. 30 ad ed.); D. 16,3,24 (Pap. 9 quaest.); D. 16,3,26,1 (Paul. 4 resp.); D. 17,1,34pr. (Afr. 8 quaest.); D. 19,5,18 (Ulp. 30 ad ed.). La bibliografía especializada es muy abundante y no corresponde tratarla en detalle en esta sede, por lo que nos remitimos a las exposiciones de conjunto de Valmaña Ochaita, Alicia, El depósito irregular en la jurisprudencia romana (Madrid, Edisofer, 1996); KLAMI, Hannu Tapani, 'Mutua magis videtur quam deposita'. Über die Geldverwahrung im Denken der römischen Juristen (Helsinki, Societas Scientiarum Fennica, 1969). Con especial consideración de la recepción de esta figura en el derecho chileno, GUZMÁN BRITO, Alejandro, Los actos y contratos irregulares en el derecho chileno (Santiago, Ediciones Universidad Católica de Chile, 2016), pp. 79 ss., 85 ss. para su origen histórico.

${ }^{27} \mathrm{El}$ contenido de los digesta de Alfeno ha llegado hasta nosotros a través de dos epítomes, a saber, los digesta ab Anonymo epitomata y los Alfeni digesta a Paulo epitomata. Si bien el Index Florentinus se refiere genéricamente a Alfeni dig. Libri 40, podemos encontrar en el Digesto de Justiniano distinas inscripciones, tales como Alfenus o Alfenus Varus libro [...] digestorum, Paulus libro [...] epitomarum Alfeni digestorum o Alfenus libro [...] digestorum a Paulo epitomatorum. La doctrina habitualmente ha atribuido estas diferencias a una negligencia de los compiladores. En lo que
} 
Saufeii cum complures frumentum confuderant, Saufeius uni ex his frumentum reddiderat de communi et navis perierat: quaesitum est, an ceteri pro sua parte frumenti cum nauta agere possunt oneris aversi actione. respondit rerum locatarum duo genera esse, ut aut idem redderetur (sicuti cum vestimenta fulloni curanda locarentur) aut eiusdem generis redderetur (veluti cum argentum pusulatum fabro daretur, ut vasa fierent, aut aurum, ut anuli): ex superiore causa rem domini manere, ex posteriore in creditum iri. idem iuris esse in deposito: nam si quis pecuniam numeratam ita deposuisset, ut neque clusam neque obsignatam traderet, sed adnumeraret, nibil alius eum debere apud quem deposita esset, nisi tantundem pecuniae solveret. secundum quae videri triticum factum Saufeii et recte datum. quod si separatim tabulis aut heronibus aut in alia cup a clusum uniuscuiusque triticum fuisset, ita ut internosci posset quid cuiusque esset, non potuisse nos permutationem facere, sed tum posse eum cuius fuisset triticum quod nauta solvisset vindicare. et ideo se improbare actiones oneris aversi: quia sive eius generis essent merces, quae nautae traderentur, ut continuo eius fierent et mercator in creditum iret, non videretur onus esse aversum, quippe quod nautae fuisset: sive eadem res, quae tradita esset, reddi deberet, furti esse actionem locatori et ideo supervacuum esse indicium oneris aversi. sed si ita datum esset, ut in simili re solvi possit, conductorem culpam dumtaxat debere (nam in re, quae utriusque causa contraheretur, culpam deberi) neque omnimodo culpam esse, quod uni reddidisset ex frumento, quoniam alicui primum reddere eum necesse fuisset, tametsi meliorem eius condicionem faceret quam ceterorum" 28 .

A propósito de la misteriosa actio oneris aversi, relativa a la pérdida de la mercancía transportada por $\operatorname{mar}^{29}$, el jurista tardorepublicano distingue entre dos géneros de res locatae (duo genera rerum locatorum) ${ }^{30}$ : tratándose de cosas que permanecen clusae u obsignatae (en el ejemplo de Alfeno: prendas de vestir que un lavandero debe lavar), no se advierten cambios en su propiedad, conservándola el locator (rem domini manere), quien puede exigir la restitución de la res ipsa (idem redderetur); en cambio, con respecto a cosas fungibles que no están clusae ni obsignatae (en el ejemplo del fragmento: cierta cantidad de plata u oro con la cual un orfebre debe confeccionar un jarrón o un anillo), el conductor adquiere la propiedad de las mismas $\mathrm{y}$, en consecuencia, debe restituir al locator otras tantas del mismo género y calidad (eiusdem generis redderetur), situación que el jurista califica explícitamente como un supuesto de credere (in creditum iri). Luego, a juicio de Alfeno, la así llamada locatio

respecta al epitome de Paulo, WiEACKer, Franz, Römische Rechtsgeschichte (München, C.H. Beck, 1988), I, p. 608 (n. 83), asume que los compiladores pudieron tener a la vista dos ejemplares con distinto título.

${ }^{28}$ Una exégesis detallada del fragmento, desde la perspectiva de la evolución histórica del credere, en Albanese, Bernardo, Per la storia del creditum, cit. (n. 16), pp. 88 ss.

${ }^{29}$ En opinión de Lenel, Otto, Das Edictum Perpetuum. Ein Versuch zu seiner Wiederherstellung ${ }^{3}$ (1883, Leipzig, Tauchnitz, 1927), p. 300, se trataría de una actio ex delicto que no fue recogida en la redacción definitiva del edicto pretorio atribuida a Salvio Juliano. Con independencia de la difícil verificabilidad de esta conjetura, lo cierto es que fuera del fragmento de Alfeno-Paulo no hay rastro alguno de la actio oneris aversi en todo el corpus de fuentes jurídicas romanas.

${ }^{30} \mathrm{En}$ las fuentes romanas el contrato de transporte marítimo es calificado como locatioconductio operis faciendi, p.ej. en D. 14,2,2pr. (Paul. 34 ad ed.); D. 19,2,11,3 (Ulp. 32 ad ed.); D. 19,2,13,1 (Ulp. 32 ad ed.) y D. 19,2,25,7 (Gai. 10 ad ed. prov.). Sobre los duo genera rerum locatorum aludidos por Alfeno véase FIORI, Roberto, La definiz̧ione della 'locatio conductio'. Giurisprudenz̧a romana e tradizione romanistica (Napoli, Jovene, 1999), pp. 65 ss.; Roтн, Hans-Jörg, Alfeni Digesta. Eine spätrepublikanische Juristenschrift (Berlin, Duncker \& Humblot, 1999), pp. 134 ss. 
conductio irregularis constituye una causa crediticia, en tanto en cuanto implica la transferencia de dominio de un certum, con la consiguiente obligación de restituir el tantundem eiusdem generis, tal como ocurre con la mutui datio.

A mayor abundamiento, la distinción entre los duo genera rerum locatarum es ilustrada por Alfeno por medio del así llamado depositum irregulare (idem iuris esse in deposito [...] tantundem pecuniae solveret), figura que igualmente se caracteriza por la transferencia de dominio sobre un certum del depositante al depositario y la respectiva obligación restitutoria del tantundem y, por ende, da lugar a un credere (res deposita in creditum ita), lo cual generó discrepancias en el seno de la jurisprudencia romana en torno a la distinción entre esta figura y el mutuum ${ }^{31}$, cuestión esta última que se encuentra en estrecha relación con la explícita distinción entre credere y deponere que se aprecia en D. 42,5,24,2, como se verá más adelante ${ }^{32}$.

En consecuencia, si bien las fuentes analizadas dan cuenta de una ampliación de la noción originaria del credere, éste se identifica todavía con supuestos de transferencia del dominio de res certae (certum dare), ya sea en virtud de una mutui datio o de negocios con efecto translaticio analogables a ella (re certum dare), de una stipulatio certi (verbis certum dare) o de una expensilatio (litteris certum dare), todos ellos unificados entre sí por la ejercitabilidad de la condictio ${ }^{33}$.

Esto es, a grandes rasgos, lo que sabemos respecto a la evolución histórica de la noción de credere con anterioridad a la fijación definitiva del contenido del edicto pretorio por Salvio Juliano, a lo que podemos denominar como credere pre-edictal.

\section{D. 12,1,1,1 (ULP. 26 AD ED.) Y EL CREDERE EDICTAL}

Punto de partida para la comprensión de la estructura y el contenido del título de rebus creditis del edictum perpetuum (título XVII, según la reconstrucción de Lenel) ${ }^{34}$ en época clásica y, con ello, del credere edictal, es un fragmento de Ulpiano, incluido por los compiladores a la cabeza del libro décimo segundo del Digesto, cuya rúbrica reza de rebus creditis, si certum petetur, et de condictione. Se trata de D. 12,1,1,1 (Ulp. 26 ad ed.): "Quoniam igitur multa ad contractus varios pertinentia iura sub hoc titulo praetor inseruit, ideo rerum creditarum titulum praemisit: omnes enim contractus, quos alienam

\footnotetext{
${ }^{31}$ Una apretada síntesis de la cuestión en ADAms, Bertrand, Haben die Römer 'depositum irregulare' und Darlehen unterschieden?, en SDHI., 28 (Città del Vaticano, 1962), pp. 360 ss.

${ }^{32}$ Infra, III.

${ }^{33}$ A juicio de Cannata, Carlo Augusto, La 'distinctio' re-verbis-litteris-consensu et les problèmes de la pratique, en Sein und Werden im Recht. Festgabe für Ulrich von Lübtow (Berlin, Duncker \& Humblot, 1970), pp. 431 ss., en la tripartición de los fundamentos del agere per condictionem estaría el origen de la clasificación de las obligaciones contractuales en re, verbis y litteris contrabere, a las que posteriormente se añadiría el consensu contrahere. Cfr. Gai. 3,89; D. 46,3,80 (Pomp. 4 ad Q. Muc.). Véase también ÉL MISMO, Sulla 'divisio obligationum' nel diritto romano repubblicano e classico, en Iura, 21 (Napoli, 1970), pp. 53 ss.; ÉL MISMO, Materiali per un corso di fondamenti del diritto europeo (Torino, Giappichelli, 2008), II, pp. 38 ss.

${ }^{34}$ Lenel, Otto, Das Edictum Perpetuum, cit. (n. 29), pp. 231 ss. En su reconstrucción del edicto pretorio, Lenel subdividó este título en las siguientes rúbricas: si certum petetur (\$95), de eo quod certo loco dari oportet (\$96), de pecunia constituta (\$97), commodati [vel contra] (\$98), de pigneraticia actione [vel contra] (\$99) y de compensationibus (\$100).
} 
fidem secuti instituimus, complectitur: nam, ut libro primo quaestionum Celsus ait, credendi generalis appellatio est: ideo sub hoc titulo praetor et de commodato et de pignore edixit. nam cuicumque rei adsentiamur alienam fidem secuti mox recepturi quid, ex boc contractu credere dicimur. rei quoque verbum ut generale praetor elegit'.

En el marco del vigésimo sexto libro de su comentario al edicto del pretor urbano, dedicado al título de rebus creditis $^{35}$, Ulpiano, inmediatamente después de acotar que, ante todo, es preciso decir algo sobre el significado de las palabras contenidas en este título ${ }^{36}$ (probablemente por las dificultades que planteaba su interpretación $)^{37}$, da cuenta de la notable ampliación que el campo semántico del vocablo credere habría experimentado en el edictum perpetuum. En concreto, el jurista tardoclásico, siguiendo una opinión que Celso habría manifestado en un texto no conservado del primer libro de sus Quaestiones ${ }^{38}$, afirma que se configura un credere cada vez que asentimos a una cosa atenidos (abandonándonos) a la fe (lealtad) de otro, para luego recibir alguna cosa en virtud del mismo contrato: nam cuicumque rei adsentiamur alienam fidem secuti mox recepturi quid, ex hoc contractu credere dicimur. Más específicamente, Ulpiano nos informa que no solo el mutuum es una causa de creditum $^{39}$, sino que también lo son el commodatum y el pignus (ideo sub hoc titulo praetor et de commodato et de pignore edixit), a pesar de que estas dos figuras no implican una datio rei en sentido estricto (esto es, no suponen una transferencia de dominio) ${ }^{40}$, característica del credere desde sus orígenes hasta al menos la época de Alfeno, sino una mera entrega (traditio en sentido lato) privada de efectos dominicales.

De lo anterior se desprende que en un momento imposible de determinar con exactitud, pero que en todo caso es posterior a Alfeno Varo (siglo I a.C.) y anterior o, al menos, contemporáneo a Celso (siglo II d.C.), el mutuo, el comodato y la prenda habrían sido reunidos como elementos constitutivos del credere edictal y, por consiguiente, del edictum de rebus creditis, en la medida que todos ellos supondrían un adsentiri rei alienam fidem secuti ${ }^{41}$. Luego, del fragmento

${ }^{35}$ Lenel, Otto, Paling. II, cit. (n. 23), cc. 567 ss.

${ }^{36}$ D. 12,1,1 pr. (Ulp. 26 ad ed.): "E re est, priusquam ad verborum interpretationem perveniamus, pauca de significatione ipsius tituli referre".

${ }^{37}$ En este sentido Cannata, Carlo Augusto, 'Creditum'e 'obligationes', en Labeo, 20 (Napoli, 1974), p. 117; SACCOCCIO, Antonio, Si certum petetur. Dalla condictio dei veteres alle condictiones giustinianee (Milano, Giuffrè, 2002), p. 123.

${ }^{38}$ Duda, en cambio, de la proveniencia celsina de la explicación ulpianea del credere edictal SACCOCcio, Antonio, Si certum petetur, cit. (n. 37), p. 430.

${ }^{39}$ La remisión al mutuo es implícita: este negocio representa la causa de crédito por antonomasia (véanse las fuentes citadas supra, n. 17); de ahí que Ulpiano se limite a aludir a la extensión del concepto de credere a nuevos contratos, sin que estime necesario mencionar el mutuo.

${ }^{40} \mathrm{El}$ significado técnico-jurídico de dare como transferencia de dominio se encuentra ampliamente documentado en las fuentes. Véase p.ej. Gai. 2,204; 4,4; D. 17,1,47,1 (Pomp. 3 ex Plaut.); D. 22,1,4pr. (Pap. 27 quaest.); D. 32,29,3 (Lab. 2 post. a Iav. epit.); D. 45,1,75,10 (Ulp. 22 ad ed.) y, muy especialmente, D. 50,17,167pr. (Paul. 49 ad ed.): "Non videntur data, quae eo tempore quo dentur accipientis non funt". Cfr. Grosso, Giuseppe, Obbligazioni. Contenuto e requisiti della prestazione, obbligazioni alternative e generiche ${ }^{2}$ (Torino, Giappichelli, 1955), pp. 19 ss.; PASTORI, Franco, Concetto e struttura della obbligazione nel diritto romano (Milano, Cisalpino, 1985), pp. 131 ss.; Wegmann Stockebrand, Adolfo, Obligatio re contracta, cit. (n. 8), pp. 117 ss.

${ }^{41}$ En este sentido Albanese, Bernardo, Per la storia del creditum, cit. (n. 16), pp. 22 ss.; ÉL 
ulpianeo resulta que la esencia del credere edictal radicaría en que una parte efectúe la entrega no necesariamente translaticia de dominio de una o más res certae abandonándose a la fides de la contraparte, quien a su vez contrae la obligación de restituir (mox recepturi quid) otros tantos del mismo género (tantundem eiusdem generis) en el caso del mutuo ${ }^{42}$, o bien, la misma cosa (res ipsa) tratándose del comodato $^{43}$ y la prenda ${ }^{44}$. Lo dicho justifica que Paulo, igualmente en el contexto de su comentario al edictum de rebus creditis, sostenga, como adelantamos en el acápite precedente, que la relación que media entre el creditum y el mutuum es de género-especie, de guisa que el primero no se reduce a la datio (en sentido estricto) de res certae con el objeto de hacer nacer una obligación de reddere genérica, sino que también se extiende a la obligación de restituir una especie o cuerpo cierto ${ }^{45}$. Así las cosas, según el testimonio de Ulpiano, el núcleo dogmático del edictum de rebus creditis estaría constituido por el adsentiri rei alienam fidem secuti, lo que exige determinar el sentido y alcance de esta expresión.

$\mathrm{Al}$ respecto, ante todo hay que aclarar que la fides aquí aludida nada tiene que ver con la bona fides del edictum de bonae fidei iudiciis (título XIX según la reconstrucción de Lenel) ${ }^{46}$, ya que todas las acciones del título de rebus creditis son de naturaleza estrictamente restitutoria (actiones stricti iuris, según la nomenclatura bizantina) ${ }^{47}$, limitadas al simplum del valor de la cosa litigiosa (quanti ea res est $\mathrm{O}$ quanti ea res erit, según el caso), al punto que puede afirmarse que el contenido de este título se reduce a la condictio (para la restitución de lo dado en mutuum ${ }^{48}$, de

mismo, Tre studi celsini. Ancora su D. 12, 1, 1, 1: Celso e il credere, en AUPA. 34 (Palermo, 1973), pp. 77 ss.; Él mismo, Credito e credere, en Marrone, Matteo (ed.), Scritti Giuridici (Palermo, Palumbo, 1991), II, pp. 1171 ss.; ÉL mismo, Rilievi minimi sul 'credere' edittale, en Marrone, Matteo (ed.), Scritti Giuridici (Palermo, Palumbo, 1991), II, pp. 1551 ss. Cfr. también SANTOro, Raimondo, Studi sulla condictio, en AUPA. 32 (Palermo, 1971), pp. 378 ss.; Cannata, Carlo Augusto, 'Creditum' e 'obligationes', cit. (n. 37), pp. 104 ss.; MARTINI, Remo, Due testi per la storia del c.d. 'credere' edittale, en Atti del II Seminario romanistico gardesano promosso dall' Istituto milanese di diritto romano e storia dei diritti antichi, 12-14 giugno 1978 (Milano, Giuffrè, 1980), pp. 109 ss.

${ }^{42}$ Gai. 3,90: "Re contrabitur obligatio uelut mutui datione; mutui autem datio proprie in bis fere rebus contingit, quae res pondere, numero, mensura constant, qualis est pecunia numerata, uinum, oleum, frumentum, aes, argentum, aurum; quas res aut numerando aut metiendo aut pendendo in hoc damus, ut accipientium fiant et quandoque nobis non eaedem, sed aliae eiusdem naturae reddantur". En el mismo sentido D. 44,7,1,2 (Gai. 2 aur.). Cfr. D. 12,1,2pr. (Paul. 28 ad ed.)

${ }^{43}$ D. 44,7,1,3 (Gai. 2 aur.): "Is quoque, cui rem aliquam commodamus, re nobis obligatur, sed is de ea ipsa re quam acceperit restituenda tenetur".

${ }^{44}$ D. 44,7,1,6 (Gai. 2 aur.): "Creditor quoque, qui pignus accepit, re tenetur: qui et ipse de ea ipsa re quam accepit restituenda tenetur?.

${ }^{45}$ D. 12,1,2,3 (Paul. 28 ad ed.): “Creditum ergo a mutuo differt qua genus a specie: nam creditum consistit extra eas res, quae pondere numero mensura continentur sic, ut, si eandem rem recepturi sumus, creditum est. item mutuum non potest esse, nisi proficiscatur pecunia, creditum autem interdum etiam si nibil proficiscatur, veluti si post nuptias dos promittatur".

${ }^{46}$ Lenel, Otto, Das Edictum Perpetuum, cit. (n. 29), pp. 288 ss.

${ }^{47}$ I. 4,6,28: "Actionum autem quaedam bonae fidei sunt, quaedam stricti iuris [...]".

${ }^{48}$ Cfr. Gai. 3,90 (texto citado supra, n. 42). 
un indebitum ${ }^{49}$ y en el supuesto especial del agere de eo quod certo loco $0^{50}$ ) y a acciones pretorias cuyas fórmulas fueron construidas siguiendo el modelo de la condictio (así llamadas kondiktionenartige Klagen $)^{51}$, tales como las actiones commodat ${ }^{52}$ y pigneraticia in factum conceptae $e^{53}$ la actio de pecunia constituta ${ }^{54}$. En el fondo, el carácter pecuniario

${ }^{49}$ Gai. 3,91: "Is quoque, qui non debitum accepit ab eo, qui per errorem solvit, re obligatur; nam proinde ei condici potest si paret eum dare oportere, ac si mutuum accepisset [...]". La condictio del solvens contra el accipiens de un indebitum constituye el objeto de un título completo del Digesto de Justiniano, cuya rúbrica reza, precisamente, de condictione indebiti (D. 12,6). Sobre la fuente, nos permitimos la remisión a WEgmann STOCKEBRAND, Adolfo, En torno al carácter (cuasi)contractual de la solutio indebiti en las Instituciones de Gayo, en REHJ., 39 (Valparaíso, 2017), pp. 85 ss., con amplia bibliografía.

${ }^{50}$ Materia tratada principalmente en D. 13,4, cuya rúbrica reza De eo quod certo loco dari oportet. No hay en las fuentes pruebas suficientes que avalen la existencia de una acción independiente (esto es, con una fórmula procesal propia) para el agere de eo quod certo loco; todo apunta a que se trataría de la misma condictio, con algunas alteraciones menores en la intentio en cuanto al locus solutionis. Para un estudio detallado de la cuestión nos remitimos a Pulitanò, Francesca, De eo quod certo loco. Studi sul luogo convenzionale dell'adempimento nel diritto romano (Milano, Giuffrè, 2009), con exégesis de las fuentes principales y amplia bibliografía.

${ }^{51}$ Cfr. Pernice, Alfred, Labeo, cit. (n. 10), pp. 429 ss.; Kaser, Max, Quanti ea res est, cit. (n. 10), pp. 65 ss.

${ }^{52}$ Gai. 4,47: "[...] at illa formula, quae ita concepta est: Index esto. Si paret Aulum Agerium apud Numerium Negidium mensam argenteam deposuisse eamque dolo malo Numerii Negidii Aulo Agerio redditam non esse, quanti ea res erit, tantam pecuniam, iudex, Numerium Negidium Aulo Agerio condemnato. Si non paret, absolvito, in factum concepta est. Similes etiam commodati formulae sunt'. Lo anterior, sin perjuicio de que hay fuentes que atestiguan que el derecho romano clásico habría conocido igualmente una actio commodati in ius ex fide bona, la cual habría coexistido con la acción honoraria, entre ellas la recién citada: "Sed ex quibusdam causis praetor et in ius et in factum conceptas formulas proponit, veluti depositi et commodati. Illa enim formula, quae ita concepta est: [...] quidquid ob eam rem Numerium Negidium Aulo Agerio dare facere oportet ex fide bona, eius, iudex, Numerium Negidium Aulo Agerio condemnato. Si non paret, absolvito, in ius concepta est [...]". Sobre la duplicidad accional del commodatum, característica que comparte con el depositum, véase PASTORI, Franco, Il commodato in diritto romano (Bologna, Cisalpino, 1995), pp. 95 ss.; KranjC, Janez, In ius und in factum konzipierte Klageformel bei der Leibe und bei der Verwahrung, en ERnst, Wolfgang; JAKAB, Eva (eds.), Usus antiquus juris romani. Antikes Recht in lebenspraktischer Anwendung (Heidelberg, Springer-Verlag, 2005), pp. 127 ss.; Veronese, Benedetta, Buona fede e duplicità delle tutele processuali nei contratti di deposito e comodato, en Garofalo, Luigi (ed.), 'Actio in rem'e 'actio in personam'. In ricordo di Mario Talamanca (Padova, Cenam, 2011), II, pp. 239 ss.; Milazzo, Antonio, Il contratto di comodato. Modelli romani e disciplina moderna (Torino, Giappichelli, 2018), pp. 79 ss.

${ }^{53}$ Una reconstrucción de la fórmula en Lenel, Otto, Das Edictum Perpetuum, cit. (n. 29), pp. 254 ss.; Mantovani, Dario, Le formule del processo privato romano. Per la didattica delle Istituzioni di diritto romano ${ }^{2}$ (1992, Padova, CEDAM, 1999), pp. 67 ss. No hay constancia de una actio pigneraticia in ius ex fide bona en época clásica, aunque aparece en el listado de I. 4,6,28.

${ }^{54}$ Véase D. 13,5, rúbrica De pecunia constituta. A diferencia del agere de eo quod certo loco, en este caso sí se trataría de una acción autónoma, aunque muy cercana a la condictio, según se desprende de PS. 2,2,1: "Si id, quod mibi L.Titius debet, soluturum te constituas, teneris actione pecuniae constitutae". Para la fórmula de la acción véase Lenel, Otto, Das Edictum Perpetuum, cit. (n. 29), p. 251; Mantovani, Dario, Le formule, cit. (n. 53), p. 68. Para un estudio detallado de la cuestión nos remitimos a VArvaro, Mario, Sulla storia dell'editto de pecunia constituta, en Studi in onore di Remo Martini (Milano, Giuffrè, 2009), III, pp. 829 ss.; CosTA, Paolo, Pecunia constituta: ipotesi interpretative, en SDHI., 77 (Città del Vaticano, 2011), pp. 129 ss.; PLATschek, Johannes, Das Ediket de pecunia constituta. Die römische Erfüllungszusage und ibre Einbettung in den hellenistischen Kreditverkehr (München, C.H. Beck, 2013), con exégesis de las fuentes principales y amplia bibliografía. 
de la condemnatio formularia romana ${ }^{55}$ tiene como consecuencia que, al margen de las diferencias estructurales entre mutuo, comodato y prenda, tanto el mutuario como el comodatario y el acreedor pignoraticio se encuentran obligados sustancialmente a lo mismo, a saber, a la restitución del simple valor de la res litigiosa. Por ello, se puede sostener que las actiones commodati y pigneraticia in factum conceptae se manifiestan como una suerte de reflejo en el ámbito del ius honorarium de la condictio del mutuante en el marco del ius civile ${ }^{56}$.

De lo dicho resulta que aquí Ulpiano está empleando el término fides en un sentido específico, propio de las causae credendi, advirtiéndose una dicotomía entre las acciones de este título edictal, sean civiles u honorarias, por una parte, y las acciones del edictum de bonae fidei iudiciis, por la otra, circunstancia que ha dado lugar a la teoría del creditum y su contraposición del contractus, desarrollada por $\mathrm{D}^{\prime} \mathrm{Ors}^{57}$, de la cual, si bien mantenemos distancia (especialmente por su muy restringida noción de contractus, que excluye figuras a las que a nuestro entender la jurisprudencia romana sí atribuyó naturaleza contractual, como es el caso, precisamente, del mutuo, el comodato y la prenda), reconocemos empero su gran relevancia en lo que respecta a la necesidad metodológica de volver la mirada a la estructura del edicto pretorio y el así llamado sistema edictal, como también a la articulación del derecho romano como un sistema de acciones ${ }^{58}$, también en el ámbito de los contratos ${ }^{59}$.

Esta suerte de relativa homogeneidad accional del edictum de rebus creditis, construido en torno a la condictio y a acciones honorarias estrictamente restitutorias que siguen su modelo, contrasta con la heterogeneidad que se aprecia en las correspondientes figuras negociales, cuando se consideran las cosas desde una perspectiva, por así decirlo, material, circunstancia que habría demandado la

${ }^{55}$ Gai. 4,48: "Omnium autem formularum, quae condemnationem habent, ad pecuniariam aestimationem condemnatio concepta est [...]”. Véase p.ej. BuRdese, Alberto, Sulla condanna pecuniaria nel processo civile romano, en SCDR., 1 (Madrid, 1989), pp. 175 ss.; KASER, Max; HACKL, Karl, Das Römische Zivilprozessrecht (München, C.H. Beck, 1996), pp. 372 ss.

${ }^{56}$ Cfr. Kaser, Max, Studien zum römischen Pfandrecht (Napoli, Jovene, 1982), p. 62.

${ }^{57}$ Véase especialmente D’Ors, Álvaro, Re et verbis, en Moschetri, Guiscardo (ed.), Atti del Congresso Internazionale di Diritto Romano e di Storia del Diritto, Verona 27-28-29 IX 1948 (Milano, Giuffrè, 1951), III, pp. 265 ss.; ÉL MISMO, Observaciones sobre el 'edictum de rebus creditis', en SDHI., 19 (Città del Vaticano, 1953), pp. 134 ss.; ÉL MISMO, Creditum y contractus, en AHDE., 26 (Madrid, 1956), pp. 6 ss.; ÉL mismo, Creditum, cit. (n. 18), pp. 345 ss.; Él mismo, Réplicas Panormitanas I. De nuevo sobre 'creditum' (Réplica a la crítica de Albanese), en SDHI., 41 (Città del Vaticano, 1975), pp. 205 ss.

${ }^{58}$ Así, textualmente, D’Ors, Álvaro, Presupuestos críticos para el estudio del derecho romano (Salamanca, Colegio Trilingüe de la Universidad, 1943), pp. 58 ss. Cfr. Provera, Giuseppe, Diritto e azione nell'esperienza giuridica romana, en PASTORI, Franco (ed.), Studi in onore di Arnaldo Biscardi (Milano, Istituto Editoriale Cisalpino, 1983), IV, pp. 325 ss.

${ }^{59} \mathrm{Al}$ respecto vale la pena tener presentes las palabras de D’ORs, Álvaro, Recensión a Grosso, Giuseppe, Il sistema romani dei contratti (Torino, Giappichelli, 1963), en Iura, 15 (Napoli, 1964), p. 397 , las que bien pueden extenderse a la romanística en general y no únicamente al manual de Grosso: “[...] si se me permite una observación general a la 'impostazione’ de Grosso, diría que se preocupa demasiado de la sistemática de las figuras (como ya Gayo) y demasiado poco de las acciones, que es lo que realmente interesaba a los clásicos". 
explicación inicial de Ulpiano ${ }^{60}$. De hecho, no pudo escapar a la atención de este jurista ni a la de sus contemporáneos el hecho que el modo de constitución de la relación obligatoria en el mutuo, por una parte, y en el comodato y en la prenda, por la otra, difieren sustancialmente, ya que mientras el primero supone una datio rei en sentido técnico-jurídico, esto es, la transferencia de la propiedad quiritaria sobre la res, tanto el comodato como la prenda implican un mero traspaso de la possessio (naturalis en el primer caso, ad interdicta en el segundo) sobre la cosa entregada ${ }^{61}$. Luego, sería un error asumir apriorísticamente que la explícita inclusión del comodato y la prenda en el edictum de rebus creditis junto al mutuo como causas crediticias obedece a que todos estos negocios constituirían supuestos de re contrabere $\mathrm{o}$, en terminología moderna, contratos reales ${ }^{62}$.

En efecto, como ya adelantamos en el acápite anterior y hemos intentado demostrar en otros trabajos, en el corpus de fuentes jurídicas romanas no se ha conservado texto alguno en el cual se utilice el sintagma re contrabere o alguna de sus derivaciones (obligatio re contracta, re contrabitur obligatio) respecto de contratos distintos del mutuum ${ }^{63}$. Para los clásicos, re contrabere significaba, específicamente, la constitución por medio de datio rei en sentido propio de una relación obligatoria estrictamente restitutoria, de guisa que la mera concurrencia de un acto de entrega en el nacimiento de la obligatio no tenía una significación jurídica concreta, ya que la traditio podía implicar la transferencia de dominio sobre la cosa entregada, constituir a alguien en poseedor ad usucapionem, ad interdicta, o en simple possessor naturalis de la misma, según el caso. Dicho en otros términos: el nacimiento de una relación obligatoria por medio de la entrega de una cosa no debió significar para los clásicos nada en concreto, por lo que no podía servir de criterio clasificatorio

${ }^{60}$ D. 12,1,1pr. (Ulp. 26 ad ed.). Fuente citada supra, n. 36. Asimismo, es muy probable que el jurista haya sentido la necesidad de dar luces sobre la antítesis que ya en época altoclásica (siglo II d.C.) se advertía entre el contenido del edictum de rebus creditis y la práctica jurídica, atendida la notable extensión que en este último ámbito experimentó el significado de algunos conceptos derivados de credere, tales como res credita, creditor o creditum (y, en cierta medida, también pecunia credita), al punto que llegará a identificarse el creditum con toda acreencia, cualesquiera que sea su causa, y al creditor con el sujeto activo de toda relación obligatoria (acreedor); lo anterior, en claro contraste con la disciplina edictal. Así se lee en Gai. 3,124: "[...] pecuniam autem creditam dicimus non solum eam, quam credendi causa damus, sed omnem, quam tum, cum contrabitur obligatio, certum est debitum iri [...]"; D. 50,16,10 (Ulp. 6 ad ed.): "creditores accipiendos esse constat eos, quibus debetur ex quacumque actione [...]"; D. 50,16,11 (Gai. 1 ad ed. prov.): “creditorum appellatione non hi tantum accipiuntur, qui pecuniam crediderunt, sed omnes, quibus ex qualibet causa debetur".

${ }^{61}$ Sobre las distintas posiciones posesorias del comodatario y el acreedor pignoraticio véase por todos Albanese, Bernardo, Le situazioni possessorie nel diritto privato romano (Palermo, Palumbo, 1985), pp. 56 ss., 83 ss.

${ }^{62}$ Plantea correctamente el punto Albanese, Bernardo, Per la storia del creditum, cit. (n. 16), p. 33 n. 13.

${ }^{63}$ Véase Gai. 3,90 (cfr. Gai Ep. 2,9,1); D. 2,14,17pr. (Paul. 3 ad ed.); D. 44,7,1,2 (Gai. 2 aur.); D. 44,7,52,1 y 3 (Mod. 2 reg.); D. 46,3,80 (Pomp. 4 ad Q. Muc.); I. 3,14pr. Cfr. WegmanN Stockebrand, Adolfo, Obligatio re contracta, cit. (n. 8), pp. 115 ss.; Él mismo, Sobre el asi llamado contrato real, cit. (n. 8), pp. 97 ss.; ÉL MISMO, Causae credendi y obligatio re contracta, cit. (n. 11), pp. 87 ss. En especial para la compleja fuente de Modestino, ÉL MISMO, ¿Re obligamur, cum res ipsa intercedit? Sobre el asi llamado contrato real en Modestino, en RCbD., 46/3 (2019), pp. 669 ss. 
de las obligationes ex contractu ${ }^{64}$. Fuera del hecho que tanto en el mutuo como en el comodato y en la prenda la causa obligationis supone la entrega de una cosa, no hay entre estas figuras (consideradas desde un punto de vista material) nada más en común, lo que es muy poco para configurar una categoría contractual propiamente dicha ante tal heterogeneidad estructural y funcional ${ }^{65}$. En consecuencia, la unificación del mutuo, el comodato y la prenda en el edictum de rebus creditis no puede radicar en la eficacia contrahendi causa de la entrega, ya que, por lo demás, de lo contrario habría sido de esperar también la inclusión del depósito en este título edictal, lo que según el testimonio de Ulpiano no ocurrió.

De lo precedentemente expuesto se desprende que el adsentiri rei alienam fidem secuti de D. 12,1,1,1 no dice relación ni con la bona fides del título edictal XIX ni con el re contrahere, debiendo aludir a algo diferente. Si analizamos el verbo adsentire, resulta que no cabe traducirlo simplemente como consentir; por el contrario, significa más bien aprobar o secundar algo ${ }^{66}$, por lo que en este contexto, en el que se vincula el verbo adsentire con un alienam fidem secuti, habría que traducirlo como aprobar la oferta o propuesta de alguien o secundarla, o más específicamente, asentir a la entrega de una cosa, confiando en que quien la recibe en su propio interés restituirá posteriormente el tantundem o la res ipsa, según el caso (mox recepturi $)^{67}$. En otros términos: la esencia del credere edictal radicaría en que el mutuante, el comodante y el deudor pignoraticio adhieren a la solicitud formulada, respectivamente, por el mutuario, el comodatario y el acreedor pignoraticio (directos interesados en el negocio), para entregarles la res objeto del contrato, quedando sujeta la obligación restitutoria de estos últimos a su fides ${ }^{68}$.

Lo anterior permite comprender por qué, según el comentario de Ulpiano, el depositum no habría encontrado cabida en el edictum de rebus creditis y, por tanto, estaría excluido de la categoría de las causae credendi: si bien en el depósito se presenta igualmente una fides aliena (en sentido amplio), como en todos los contratos, incluido el mutuo ${ }^{69}$, no se configura propiamente un adsentiri rei en orden a un

${ }^{64}$ En este sentido ya Perozzi, Silvio, Istituzioni di diritto romano ${ }^{2}$ (Roma, Athenaeum, 1928), II, p. 32 (n. 1): "La frase: contratto che si fa colla cosa (re) non significa infatti nulla; ed è enorme in ogni caso riassumere in un'unica categoria per il modo di perfezionamento contratti che si perfezionano colla trasmissione del dominio e contratti che si perfezionano dando una cosa, di cui il dante conserva la proprietà e il possesso o sempre o agli effetti almeno dell'usucapione come nel pegno".

${ }^{65}$ Ya lo había hecho notar Schulz, Fritz, Classical Roman Law (Oxford, Oxford University Press, 1951), p. 469: "[...] otherweise the contracts assembled in this group have nothing in common". En términos similares QuAdrato, Renato, Le Institutiones nell'insegnamento di Gaio. Omissioni e rinvii (Napoli, Jovene, 1979), p. 78, se preguntaba por "le ragioni di presenze così eterogenee in una stessa categoria".

${ }^{66}$ Heumann, Hermann Gottlieb; Seckel, Emil, Handlexikon, cit. (n. 13), p. 18. Albanese, Bernardo, Per la storia del creditum, cit. (n. 16), p. 34, traduce adsentire como "dare la propria adesione ad alcunchè di presupposto, di proposto da altri”.

${ }^{67}$ Cfr. Albanese, Bernardo, Per la storia del creditum, cit. (n. 16), p. 33; SAntoro, Raimondo, Studi sulla condictio, cit. (n. 42), p. 378; Jung, Byoung-Ho, Darlehensvalutierung im römischen Recht (Göttingen, Wallstein, 2002), p. 44.

${ }^{68}$ Albanese, Bernardo, Per la storia del creditum, cit. (n. 16), pp. 31 ss.

${ }^{69}$ Cfr. Giuffrè, Vincenzo, La 'datio mutui'. Prospettive romane e moderne (Napoli, Jovene, 1989), p. 32. 
alienam fidem secuti, ya que de parte del depositante no hay una deliberación adhesiva a la propuesta del depositario ni, por tanto, un acto de fe en los términos del credere edictal. En efecto, la entrega de la res deposita tiene como único beneficiario el depositante, de manera que, tanto estructural como funcionalmente, éste no adhiere a una propuesta del depositario ni se abandona a su fides, de manera que no credit en el sentido del edicto. Por lo demás, lo dicho justifica que la responsabilidad del depositario esté limitada al dolo ${ }^{70}$ (y, por consiguiente, también a la culpa lata $)^{71}$, en virtud del principio de la utilitas contrahentium, al no reportar esta parte utilidad alguna del negocio ${ }^{72}$. En cambio, tanto en el mutuo (prototipo del credere) como en el comodato y en la prenda, figuras tipificadas en el edicto como causae credendi, es la parte que recibe la cosa (mutuario, comodatario y acreedor pignoraticio, respectivamente) la que reporta utilidad de la operación y toma la iniciativa para su conclusión, como da cuenta el empleo en las fuentes del verbo rogare y otras expresiones semejantes ${ }^{73}$ que, en cambio, no se aprecian en fuentes relativas al depósito.

En pocas palabras: del fragmento ulpianeo se desprende que el depositante confía en el comportamiento leal del depositario (el cual, como hemos visto, está limitado a un grado mínimo de diligencia) pero no sigue su fides (no se configura un alienam fidem secuti en sentido edictal) ni hay tampoco propiamente un adsentiri rei, elementos que, en cambio, sí se presentan en el mutuo, el comodato y la prenda, circunstancia ésta que justificaría a los ojos de Ulpiano la incorporación de estos

${ }^{70}$ Esto se aprecia en la aplicación al dolus de expresiones tales como solus, tantum, dumtaxat, non ultra, las cuales manifiestan la idea de que el depositario no responde más allá de un comportamiento doloso. Véase p.ej. Gai. 3,107; D. 4,9,3,1 (Ulp. 14 ad ed.); D. 13,1,16 (Pomp. 38 ad Q. Muc.); D. 16,3,1,1, 18 y 33 (Ulp. 30 ad ed.); D. 16,3,13pr. (Paul. 31 ad ed.); D. 16,3,20 (Paul. 18 ad ed.); D. 19,5,17,2 (Ulp. 28 ad ed.); D. 47,2,14,3 (Ulp. 29 ad Sab.); D. 50,17,23 (Ulp. 29 ad Sab.). Cfr. Litewski, Wieslaw, Depositary's liability in Roman Law, en AG., 190 (Modena, 1976), pp. 4 ss.; Rotond, Giovanni, Contributi alla storia del contratto di deposito nel diritto romano. La misura della responsabilità nell'actio depositi, en Arangio-Ruiz, Vincenzo; Albertario, Emilio; De Francisci, Pietro (eds.), Scritti giuridici (Milano, Ulrico Hoepli, 1922), II, pp. 91 ss.

${ }^{71}$ D. 11,6,1,1 (Ulp. 24 ad ed.): “[...] lata culpa plane dolo comparabitur [...]".

${ }^{72}$ Así lo expresa con nitidez el propio Ulpiano en D. 13,6,5,2 (Ulp. 28 ad ed.): "Nunc videndum est, quid veniat in commodati actione, utrum dolus an et culpa an vero et omne periculum. et quidem in contractibus interdum dolum solum, interdum et culpam praestamus: dolum in deposito: nam quia nulla utilitas eius versatur apud quem deponitur, merito dolus praestatur solus [...]"; D. 50,17,23 (Ulp. 29 ad Sab.): "Contractus quidam dolum malum dumtaxat recipiunt, quidam et dolum et culpam. dolum tantum: depositum et precarium [...]”. En detalle sobre la regla de responsabilidad contractual que de aquí se desprende, TAFAro, Sebastiano, Regula e ius antiquum in D.50.17.23. Ricerche sulla responsabilità contrattuale (Bari, Cacucci, 1984). Una visión de conjunto sobre el desarrollo histórico de la regla de la utilitas contrahentium desde el derecho romano hasta las modernas codificaciones civiles en SANTUCCI, Gianni, Il principio dell'utilità dei contraenti, en Diritto romano e diritti europei. Continuità e discontinuità nelle figure giuridiche ${ }^{2}$ (Bologna, Il Mulino, 2018), pp. 69 ss.

${ }^{73}$ Así p.ej. en D. 12,1,4pr. (Ulp. 34 ad Sab.): “[...] desideravis mutuam pecuniam [...]”; D. 12,1,11pr. (Ulp. 26 ad ed.): "Rogasti me, um tibi pecuniam crederem [...]"; D. 12,1,32 (Cels. 5 dig.): "Si et me et Titium mutuam pecuniam rogaveris [...]"; D. 13,6,5,6 (Ulp. 28 ad ed.): "[...] is qui rogavit [...]”; D. 13,6,5,7 (Ulp. 28 ad ed.): "[...] eum qui commodatum rogavit". 
dos últimos contratos al edictum de rebus creditis, por una parte, y la exclusión del depósito, por la otra ${ }^{74}$.

A mayor abundamiento, tampoco se encuentran en las fuentes de que disponemos argumentos textuales que justifiquen la tesis defendida por algunos autores, según la cual en un momento histórico que éstos no especifican, pero que evidentemente debió ser anterior a la fijación definitiva del albo pretorio por Salvio Juliano, el depósito habría encontrado protección procesal en el marco del edictum de rebus creditis, para luego ser absorbido por el título edictal de bonae fidei indiciis $^{75}$. En realidad, como ya ha hecho notar Albanese, se trata de una doctrina sustentada únicamente en una petición de principio, a saber, por una parte, que tanto el mutuo como el comodato, la prenda y el depósito habrían sido obligationes re contractae en época clásica, y por la otra, que el título edictal de rebus creditis y la categoría de los así llamados contratos reales no serían sino dos caras de la misma moneda (una procesal, la otra sustantiva) ${ }^{76}$; lo cual impondría la necesidad de encontrar una justificación al hecho que el depósito sea (según estos autores) la única obligatio re contracta excluida del catálogo de causae credendi $i^{77}$.

Por el contrario, sobre la base de los datos que nos entregan las fuentes, de lo único que a este respecto podemos estar seguros es que, a partir de una primitiva protección penal del interés del depositante por medio del otorgamiento de una actio in duplum ${ }^{78}$, el pretor (en una época difícil de determinar con exactitud, pero que probablemente tuvo lugar en el siglo I a.C. $)^{79}$ habría creado una acción

${ }^{74}$ Albanese, Bernardo, Per la storia del creditum, cit. (n. 16), pp. 35 ss.

${ }^{75}$ En este sentido p.ej. MAsCHI, Carlo Alberto, La categoria dei contratti reali. Corso di diritto romano (Milano, Giuffrè, 1973), pp. 226 ss.; Bonfante, Pietro, Istituzioni di diritto romano ${ }^{10}$ (Roma, Istituto di Diritto Romano, 1934), p. 404 n. 1.

${ }^{76}$ Así Maschi, Carlo Alberto, La categoria dei contratti reali, cit. (n. 75), pp. 254 ss. En este orden de cosas, Castresana Herrero, Amelia, Derecho romano. El arte de lo bueno y de lo justo (Madrid, Tecnos, 2013), p. 199, incurre en el error de incluir de plano al depósito entre las figuras protegidas en el edictum de rebus creditis: "Las relaciones protegidas en el Edicto son cuatro: la pecunia constituta, el commodatum, el pignus y el depositum. En todas ellas, a excepción de la pecunia constituta, subsiste la entrega de bienes como elemento tipico constitutivo de compromiso [...]. Hay una simple consigna de bienes que el pretor descubre como principio operativo en la relación de crédito, lo cual no deja de recordarnos el valor vinculante de la entrega material de cosas (= elemento real = re obligatio contracta)".

${ }^{77}$ Albanese, Bernardo, Per la storia del creditum, cit. (n. 16), p. 33 (n. 13): "Alla base di tutte le difficoltà sta chiaramente la convinzione, a nostro avviso infondata, di una coincidenza, o comunque di una stretta relazione, tra il credere edittale e la formazione della categoria dei c.d. contratti reali comprensiva del mutuo, commodato, deposito e pegno".

${ }^{78}$ PS. 2,12,11=Coll. 10,7,11: "Ex causa depositi lege duodecim tabularum in duplum actio datur, edicto praetoris in simplum". Sobre la fuente, véase GANDOLFI, Giuseppe, Il deposito nella problematica della giurisprudenza romana (Milano, Giuffrè, 1976), pp. 46 ss.; Evans-Jones, Robin, The action of the XII Tables 'ex causa depositi', en Labeo, 34 (Napoli, 1988), pp. 188 ss.; Scheibelreiter, Philipp, Zwischen furtum und Litiskreszen₹: Überlegungen zurpoena dupli der actio ex causa depositi, en RID A., 56 (Liège, 2009), pp. 131 ss.; ÉL MISMO, Infitiando depositum nemo facit furtum? Zu den Urspruüngen der Verwahrerhaftung, en Buongionno, Pierangelo; Lohsse, Sebastian (eds.), Fontes Iuris. Atti del VI Jabrestreffen Junger Romanistinnen und Romanisten. Lecce, 30-31 marzo 2012 (Napoli, Edizioni Scientifiche Italiane, 2013), pp. 179 ss. Una visión de conjunto sobre la evolución histórica del contrato de depósito en Astuti, Guido, Deposito (storia), en ED., 12 (Milano, Giuffrè, 1964), pp. 212 ss.

${ }^{79}$ Cfr. Gandolfi, Giuseppe, Il deposito, cit. (n. 78), pp. 90 ss., con análisis de las fuentes pertinentes. 
honoraria limitada al simplum del valor de la res deposita y, por tanto, de naturaleza estricamente restitutoria, rasgo que comparte con la condictio: la actio depositi in factum concepta, cuya fórmula nos es conocida gracias al magisterio de Gayo, y que encontraba el supuesto fáctico de condena del reus en la dolosa falta de restitución de la cosa $([\ldots] \text { dolo malo }[\ldots] \text { redditam non esse })^{80}$.

Asimismo, muy probablemente en el curso del siglo I d.C. se introdujo una actio depositi in ius ex fide bona, cuya fórmula igualmente nos es conocida por medio de Gayo y que convivió con la acción pretoria durante el resto de la época clásica $^{81}$. Cabe destacar que la actio in ius no se funda en la negativa dolosa del depositario a restituir, sino que se remite genéricamente a todo aquello que éste debe dar o hacer según el criterio de la buena fe, motivo por el cual la condena no se vincula al simple valor de la res deposita (quanti era res erit), como ocurre en la fórmula in factum, sino más bien al interés del acreedor (id quod interest actoris), circunstancia que amplía notablemente los supuestos de incumplimiento y el margen de apreciación del iudex para condenar al depositario infiel ${ }^{82}$.

Pues bien, si por una parte no pasa de ser una mera conjetura carente de sustento textual en las fuentes la idea consistente en que el depósito, de una posición originaria en el edictum de rebus creditis, habría sido absorbido por el edictum de bonae fidei iudiciis, por la otra, incluso en la eventualidad de ser cierta tal conjetura, se presentaría un nuevo problema de tan difícil o imposible solución, como es el motivo por el cual la supuesta fuerza absorbente del título edictal sobre las acciones de buena fe no habría sido eficaz en el caso del comodato, en circunstancia que no solo Gayo, sino que también una serie de fragmentos del Digesto que están más allá de toda duda sobre su autenticidad, atestiguan que el

${ }^{80}$ Gai. 4,47: "[...] at illa formula, quae ita concepta est: Iudex esto. Si paret Aulum Agerium apud Numerium Negidium mensam argenteam deposuisse eamque dolo malo Numerii Negidii Aulo Agerio redditam non esse, quanti ea res erit, tantam pecuniam, iudex, Numerium Negidium Aulo Agerio condemnato. Si non paret, absolvito, in factum concepta est [...]”. Cfr. D 16,3,1,1 (Ulp. 30 ad ed.), donde el jurista tardoclásico parece citar directamente el texto del edicto. Sobre la responsabilidad del depositario por non reddere en el marco de esta acción véase Panero Gutiérrez, Ricardo, El depósito, en Paricio SERRANO, Javier (ed.), Derecho romano de obligaciones. Homenaje al profesor José Luis Murga Gener (Madrid, Centro de Estudios Ramón Areces, 1994), pp. 270 ss. Más ampliamente Él mismo, Deponere y reddere en la actio depositi in factum (Barcelona, Promociones y Publicaciones Universitarias, 1989).

${ }^{81}$ Gai. 4,47: "C. Aquilius iudex esto. Quod A. Agerius apud N. Negidium mensam argenteam deposuit, qua de re agitur, quidquid ob eam rem N. Negidium A. Agerio dare facere oportet ex fide bona, eius C. Aquilius iudex N. Negidium A. Agerio condemnato; si non paret absolvito [...]". Sobre la duplicidad formularia del depósito véase especialmente WALTER, Tom, Die Funktionen der actio depositi (Berlin, Duncker \& Humblot, 2012), pp. 33 ss.; Veronese, Benedetta, Buona fede e duplicità delle tutele processuali, cit. (n. 52), pp. 239 ss.; KRANJC, Janez, In ius und in factum konzipierte Klageformel, cit. (n. 52), pp. 127 ss.; CASTRO SÁEnZ, Alfonso, Responsabilidady duplicidad formularia: los casos del depósito y el comodato en la época clásica, en Murillo ViLlar, Alfonso (ed.), La responsabilidad civil: de Roma al derecho moderno (Burgos, Universidad de Burgos, 2001), pp. 187 ss.; GAndolfi, Giuseppe, Il deposito, cit. (n. 78), pp. 69 ss.; Burillo Loshuertos, Jesús, Las fórmulas de la 'actio depositi', en SDHI., 28 (Città del Vaticano, 1962) pp. 233 ss.; RoTONDI, Giovanni, Contributi alla storia del contratto di deposito nel diritto romano. Le due formule classiche dell'actio depositi, en ArAngio-Ruiz, Vicenzo; Albertario, Emilio; De Francisci, Pietro (eds.), Scritti giuridici (Milano, Ulrico Hoepli, 1922), II, pp. 1 ss.

${ }^{82}$ Cfr. Panero Gutiérrez, Ricardo, El depósito, cit. (n. 80), pp. 276 ss.; Gandolfi, Giuseppe, Il deposito, cit. (n. 78), p. 95; RoTONDI, Giovanni, La misura della responsabilità, cit. (n. 70), pp. 91 ss. 
derecho romano clásico conoció tanto una actio commodati in factum (estrictamente restitutoria) como una concebida en el derecho y de buena fe (actio commodati in ius ex fide bona $)^{83}$. Sin embargo, como ya hemos visto, consta que en su comentario al título edictal de rebus creditis, Ulpiano (siguiendo en esto muy probablemente a Celso) fue explícito al incluir el comodato (y también la prenda) en el catálogo de causae credendi, omitiendo, en cambio, toda referencia al depósito.

En definitiva, a nuestro entender, en D. 12,1,1,1 se trata de una marginación del deponere de la categoría del credere sobre la base de consideraciones por así decirlo materiales, fundadas en la estructura negocial y la función económica del depositum, no en razón de los instrumentos procesales que protegen el interés del depositante, ámbito este último en el que sí se advierte cierta simetría entre depósito, mutuo, comodato y prenda, al menos según el punto de vista de Gayo y Paulo, como ya se dijo ${ }^{84}$.

\section{D. 42,5,24,2 (ULP. 63 AD ED.): ALIUD EST ENIM CREDERE,} ALIUD DEPONERE

A partir de lo expuesto en el acápite precedente no debe sorprender que la exclusión del depositum de la noción de credere sea explicitada en otra fuente ulpianea: D. 42,5,24,2 (Ulp. 63 ad ed.): "In bonis mensularii vendundis post privilegia potiorem eorum causam esse placuit, qui pecunias apud mensam fidem publicam secuti deposuerunt. Sed enim qui depositis nummis usuras a mensulariis acceperunt a ceteris creditoribus non separantur, et merito: aliud est enim credere, aliud deponere. si tamen nummi exstent, vindicari eos posse puto a depositariis et futurum eum qui vindicat ante privilegia".

El contexto palingenésico de este fragmento es el comentario de Ulpiano al edicto pretorio en materia de ejecución patrimonial de las obligaciones (bonorum venditio) y, más específicamente, de los privilegios de los acreedores (de privilegiariis

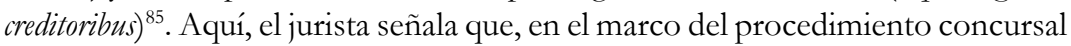
seguido contra un banquero insolvente, entre los múltiples acreedores se otorga una preferencia a quienes depositaron su dinero en el banco ateniéndose a la fe pública (apud mensam fidem publicam secuti deposuerunt), expresión ésta que, curiosamente, es muy similar a la utilizada en D. 12,1,1,1, donde la esencia del credere (de la cual se excluye implícitamente el depósito) se identifica con un adsentiri rei alienam fidem secuti. En cambio, agrega Ulpiano, no se distinguen de los demás acreedores (esto es, carecen de preferencia) quienes recibieron del banquero el pago de intereses por el dinero depositado, precisamente porque una cosa es dar en crédito y otra depositar: aliud est enim credere, aliud deponere.

En el marco de la actividad financiera romana, había clientes bancarios que

${ }^{83}$ Véase supra, n. 52.

${ }^{84}$ Véase D. 44,7,1,2-6 (Gai. 2 aur.) para Gayo (asumiendo su autoría de las res cottidianae), cuyo texto es citado en lo pertinente supra, n. 7; D. 16,3,13,1 (Paul. 31 ad ed.) para Paulo, citado supra, n. 5.

${ }^{85}$ Lenel, Otto, Paling. II, cit. (n. 23), cc. 793 ss. Véase especialmente Solazzi, Siro, Il concorso dei creditori nel diritto romano (Napoli, Jovene, 1940), III, pp. 114 ss. 
depositaban sumas de dinero en bolsas cerradas y selladas (clusae u obsignatae) ${ }^{86}$; la expresión si tamen nummi exstent, si las monedas todavía existieran, debe ser entendida en el sentido de monedas susceptibles de individuación, lo que únicamente podía ocurrir si se encontraban separadas de las demás, precisamente porque estaban contenidas en un recipiente cerrado. En tal caso, regían plenamente las reglas relativas al depósito, en particular, la prohibición para el argentarius de utilizar el dinero recibido ${ }^{87}$ y la consiguiente obligación de restituir las mismas monedas (res ipsa), en vez de otros tantos del mismo género (tantundem eiusdem generis) ${ }^{88}$.

Otros clientes, en cambio, optaban por depositar sumas de dinero autorizando al banquero a emplearlas, de manera que su obligación restitutoria era de género, sin que por ello estos clientes percibieran intereses. Su existencia se deduce de la referencia contenida en el fragmento en comento a la preferencia de quienes, siguiendo la fe pública, han depositado su dinero en el banco, y su distinción explícita de quienes reciben intereses ([...] potiorem eorum causam esse placuit, qui pecunias apud mensam fidem publicam secuti deposuerunt. Sed enim qui depositis nummis usuras a mensulariis acceperunt a ceteris creditoribus non separantur $[\ldots])^{89}$.

Finalmente, había un tercer grupo de clientes, los cuales depositaban su dinero en el banco con la finalidad de recibir intereses a cambio de autorizar al argentarius para darlo en préstamo a terceros; intereses que podían nacer ya sea en virtud de un pacto entre del depositante y el banquero (usurae ex pacto) ${ }^{90}$, o bien, de la simple circunstancia que el argentarius utilizara el dinero para sus propios fines comerciales (pecunia in re sua usus est) ${ }^{91}$, en ambos casos, en el marco del ejercicio de la actio depositi in ius ex fide bona. Estos clientes, explica Ulpiano, no se distinguen de los demás acreedores y, lo más importante para efectos de nuestro estudio, no

${ }^{86}$ Cfr. D. 19,2,31 (Alf. 5 dig. a Paulo epit.).

${ }^{87}$ En caso contrario, podría configurarse un supuesto de furtum usus del banquero depositario. Así se lee en Gai. 3,196: "Itaque si quis re, quae apud eum deposita sit, utatur, furtum committit”. Véase también D. 13,1,16 (Pomp. 38 ad Q. Muc.); D. 47,2,77pr. (Pomp. 38 ad Q. Muc.). Según el testimonio de Gell., Noct. Att. 6,15,2, la posibilidad de ejercitar la actio furti contra el depositario se remontaría al menos hasta los tiempos de Q. Mucio Escévola. Cfr. Gandolfi, Giuseppe, Il deposito, cit. (n. 78), pp. 54 ss.; Walter, Tom, Die Funktionen, cit. (n. 81), pp. 323 ss.

${ }^{88}$ Para lo que sigue véase Petrucci, Aldo, Mensam exercere. Studi sull'impresa finanziaria romana (II secolo a.C. - metà del III secolo d.C.) (Napoli, Jovene, 1991), pp. 209 ss.; Cerami, Pietro; Petrucci, Aldo, Diritto commerciale romano. Profilo storico ${ }^{3}$ (Torino, Giappichelli, 2010), pp. 122 ss.

${ }^{89} \mathrm{La}$ misma idea se desprende de otro fragmento ulpianeo, D. 16,3,7,2 (Ulp. 30 ad ed.): "Quotiens foro cedunt nummularii, solet primo loco ratio baberi depositariorum, boc est eorum qui depositas pecunias habuerunt, non quas faenore apud nummularios vel cum nummulariis vel per ipsos exercebant. et ante privilegia igitur, si bona venierint, depositariorum ratio habetur, dummodo eorum qui vel postea usuras acceperunt ratio non habeatur, quasi renuntiaverint deposito".

${ }^{90}$ Así se desprende de D. 16,3,24 (Pap. 9 quaest.); D. 16,3,26,1 (Paul. 4 resp.); D. 16,3,28 (Scaev. 1 resp.). Para estas fuentes véase especialmente PeTrucci, Aldo, Profili giuridici delle attività e dell'organizzazione delle banche romane (Torino, Giappichelli, 2002), pp. 70 ss. En detalle sobre los intereses nacidos de convención CHERCHI, Alice, Ricerche sulle 'usurae' convenzionali nel diritto romano classico (Napoli, Jovene, 2012), con amplia bibliografía y exégesis de las fuentes principales.

${ }^{91}$ D. 16,3,28 (Scaev. 1 resp.). Cfr. D. 16,3,29,1 (Paul. 2 sent.). 
serían depositantes en sentido propio, sino mutuantes, ya que una cosa sería dar en préstamo y otra depositar (aliud est enim credere, aliud deponere) ${ }^{92}$.

Luego, de lo que se trata, en definitiva, es de que el depósito de una suma de dinero en un banco con miras a obtener el pago de intereses, implicaría en la práctica una renuncia al depósito, como se lee en D. 16,3,7,2 (eorum qui vel postea usuras acceperunt ratio non habeatur, quasi renuntiaverint deposito), y convertiría al acreedor más bien en un prestamista (creditor en sentido estricto), lo que muestra una vez más las dificultades que enfrentaba la jurisprudencia romana en cuanto al encuadre dogmático de la figura del depositum irregulare y su relación con la mutui datio $^{93}$. Por tanto, aquí Ulpiano parece utilizar el vocablo credere en su acepción más restringida, equivalente a la dación mutuaria, no necesariamente en el sentido más amplio del edicto ${ }^{94}$, por lo que, desde este punto de vista, la fuente en comento no sería suficientemente concluyente en cuanto a una exclusión tout court del deponere del credere edictal. En efecto, más bien pareciera tratarse de la forma que, en este contexto específico, encontró Ulpiano para hacerse cargo (aunque fuera de pasada) de una práctica comercial que no se adecuaba a los esquemas contractuales tradicionales del mutuo y el depósito -por así decirlo, puros-, sino que combinaba elementos de ambas figuras, lo que condujo al jurista a evitar calificaciones precisas ${ }^{95}$.

Esta relativa ambigüedad en la forma de expresarse de Ulpiano se advierte también cuando -en fragmentos incorporados por los compiladores de Justiniano al título de de rebus creditis, si certum petetur, et de condictione del Digesto, aunque de orígenes palingenésicos muy distintos- se refiere a la delgada línea divisoria entre credere y deponere, siempre con relación al préstamo de dinero. Así leemos en D. 12,1,4pr. (Ulp. 34 ad Sab.): "Si quis nec causam nec propositum faenerandi habuerit et tu empturus praedia desideraveris mutuam pecuniam nec volueris creditae nomine antequam emisses suscipere atque ita creditor, quia necessitatem forte proficiscendi habebat, deposuerit apud te hanc eandem pecuniam, ut, si emisses, crediti nomine obligatus esses, hoc depositum periculo est eius qui suscepit. nam et qui rem vendendam acceperit, ut pretio uteretur, periculo suo rem habebit". Asimismo, encontramos en D. 12,1,10 (Ulp. 2 ad ed.) lo que sigue: "Quod si ab initio, cum deponerem, uti tibi si voles permisero, creditam non esse antequam mota sit, quoniam debitu iri non est certum" ". Finalmente, en sedes materiae de depósito, se reitera la idea de que la sola autorización para el adquirente en orden a utilizar el dinero depositado no convertiría necesariamente el negocio en un mutuo (a menos que se cobren intereses), pudiendo, por tanto, ejercitarse la acción de depósito: D.

${ }^{92}$ Cfr. Litewski, Wieslaw, Le dépôt irrégulier (II), en RID A., 22 (Liège, 1975), pp. 290 ss.; BonIFACIO, Franco, Ricerche sul deposito irregolare in diritto romano, en BIDR., 49-50 (Roma, 1947), p. 151.

${ }^{93}$ Sobre las dificultades que plantea el fragmento objeto del presente acápite para la cuestión del así llamado depositum irregulare véase Valmaña Ochaita, Alicia, El depósito irregular, cit. (n. 26), pp. 113 ss.; KLAmi, Hannu Tapani, Mutua magis videtur quam deposita, cit. (n. 26), pp. 198 ss.

${ }^{94}$ Cfr. Albanese, Bernardo, Per la storia del creditum, cit. (n. 16), p. 32.

${ }^{95}$ Cfr. Petrucci, Aldo, Mensam exercere, cit. (n. 88), pp. 213 ss.; Cerami, Pietro; Petrucci, Aldo, Diritto commerciale romano, cit. (n. 88), pp. 125 ss.

${ }^{96}$ Cfr. Saccoccio, Antonio, Si certum petetur, cit. (n. 37), p. 425 (n. 25); Petrucci, Aldo, Mensam exercere, cit. (n. 88), p. 217. 
16,3,1,34 (Ulp. 30 ad ed.): "Si pecunia apud te ab initio hac lege deposita sit, ut si voluisses utereris, prius quam utaris depositi teneberis".

Una distinción entre credere y deponere se aprecia igualmente en otras fuentes, tanto jurídicas ${ }^{97}$ como extrajurídicas $^{98}$, aunque siempre referidas al sentido más restringido y tradicional de credere como mutui datio.

\section{CONCLUSIONES Y PERSPECTIVAS}

En el presente trabajo hemos intentado demostrar que la compleja relación entre credere y deponere de que dan cuenta las fuentes analizadas es una cuestión que no contó con una valoración unívoca en la jurisprudencia romana. Así se advierte no solo en las ideas de Gayo y Paulo al respecto, que contrastan con las de Ulpiano en este punto, sino también en la forma a veces implícita, otras imprecisa, en la que el propio Ulpiano trata el problema de la aparente exclusión del depósito de la categoría de las causas crediticias.

En efecto, si por una parte Ulpiano parece excluir el deponere de la categoría del credere al omitir toda referencia al depósito en el marco de su exposición del contenido del edictum de rebus creditis (D. 12,1,1,1), circunstancia que admite una explicación basada en la estructura negocial del depositum (supra, II), por la otra, la explícita distinción entre ambas nociones a través del dictum ulpianeo aliud est enim credere, aliud deponere (D. 42,5,24,2) se inserta en una discusión de márgenes más bien acotados, cual es la relación entre el mutuo de dinero y el así llamado depósito irregular en el derecho romano clásico, de donde se sigue que el jurista tardoclásico muy probablemente emplea en esta fuente el vocablo credere y sus derivados en el sentido más estricto, tradicional y original del mismo, es decir, la mutui datio, no según su significado más amplio en el título edictal de rebus creditis, que según su propio testimonio se habría extendido al comodato y la prenda, no así al depósito (supra, III).

Así las cosas, el tratamiento del problema de la relación entre credere y deponere en los fragmentos ulpianeos estudiados parte siempre de la base de consideraciones centradas en la estructura funcional del deponere, que lo llevarían a excluirlo de la categoría del credere, ya sea omitiendo toda referencia al depositum en su explicación del contenido del edictum de rebus creditis, o bien, contraponiendo explícitamente ambas nociones en el contexto de los créditos privilegiados contra el banquero insolvente. En cambio, juristas como Gayo y Paulo se muestran más atentos a las semejanzas procesales entre deponere y credere, lo que motiva que encontremos en sus obras un tratamiento relativamente ambiguo o, si se quiere, asistemático de la cuestión, donde pareciera no haber una real incompatibilidad entre ambas categorías (D. 44,7,1,2-6 y D. 16,3,13,1, respectivamente).

${ }^{97}$ D. 46,3,35 (Alf. 2 dig. a Paul. epit.): "Quod servus ex peculio suo credidisset aut deposuisset [...]".

${ }^{98}$ QuinT., Inst. orat. 7,2,51: "[...] Crediti et depositi duae quaestiones, sed numquam iunctae, an datum sit, an redditum [...]". Este texto no ha despertado en la romanística el interés que merece. Se limita a citarlo, sin hacerse cargo del problema de la explícita distinción entre credere y deponere, WyCISK, Tonia, Quidquid in foro fieri potest - Studien zum römischen Recht bei Quintilian (Berlin, Duncker \& Humblot, 2008), p. 81. 
En otras palabras: si la consideración de la estructura funcional del mutuo, el comodato y la prenda, por una parte, y la del depósito, por la otra, lleva a Ulpiano a distinguir entre aquellas figuras y ésta, marginando el deponere del credere, las evidentes semejanzas que se aprecian en la accionabilidad de todas ellas, al estar protegidas alternativamente por la condictio o por acciones honorarias construidas según su modelo, inducen a Gayo y Paulo a su relativa asimilación. Así las cosas, el dictum ulpianeo aliud est enim credere, aliud deponere podrá ser válido para la obra de este jurista en especial, pero no lo es necesariamente para la amplia variedad de la jurisprudencia romana en general, ni tampoco puede ser visto como la síntesis de la relación entre causas crediticias y depósito en el derecho romano clásico; todo lo cual implica que el edictum de rebus creditis sigue siendo un fértil campo de investigación para la iusromanística contemporánea.

\section{BiBLIOGRAFÍA}

ADAms, Bertrand, Haben die Römer 'depositum irregulare' und Darlehen unterschieden?, en SDHI., 28 (Città del Vaticano, 1962), pp. 360-371.

Albanese, Bernardo, Per la storia del creditum, en AUPA., 32 (Palermo, 1971), pp. 5-179.

-Tre studi celsini. Ancora su D. 12, 1, 1, 1: Celso e il credere, en AUPA., 34 (Palermo, 1973), pp. 77-162.

- Le situazioni possessorie nel diritto privato romano (Palermo, Palumbo, 1985).

—Credito e credere, en Marrone, Matteo (ed.), Scritti Giuridici (Palermo, Palumbo, 1991), II, pp. 1171-1188.

—Rilievi minimi sul 'credere' edittale, en Marrone, Matteo (ed.), Scritti Giuridici (Palermo, Palumbo, 1991), II, pp. 1551-1563.

Astuti, Guido, Deposito (storia), en ED., 12 (Milano, Giuffrè, 1964), pp. 212-236.

BenKe, Nikolaus, Zum Eigentumserwerb des Unternehmers bei der 'locatio conductio irregularis', en ZSS., 104 (Graz, 1987), pp. 156-237.

Bonfante, Pietro, Istituحioni di diritto romano ${ }^{10}$ (Roma, Istituto di Diritto Romano, 1934).

BonifaCiO, Franco, Ricerche sul deposito irregolare in diritto romano, en BIDR., 49-50 (Roma, 1947), pp. 80-152.

Brasiello, Ugo, Il cosi detto deposito irregolare e la c. d. locatio operis irregolare, en Problemi di diritto romano esegeticamente valutati (Bologna, Pàtron, 1954), I, pp. 23-84.

BurdesE, Alberto, Sulla condanna pecuniaria nel processo civile romano, en SCDR., 1 (Madrid, 1989), pp. 175-203.

Burillo Loshuertos, Jesús, Las fórmulas de la 'actio depositi', en SDHI., 28 (Città del Vaticano, 1962) pp. 233-291.

Cannata, Carlo Augusto, La 'distinctio' re-verbis-litteris-consensu et les problèmes de la pratique, en Sein und Werden im Recht. Festgabe für Ulrich von Lübtow (Berlin, Duncker \& Humblot, 1970), pp. 431-455.

— Sulla 'divisio obligationum' nel diritto romano repubblicano e classico, en Iura, 21 (Napoli, 1970), pp. 52-70.

—Creditum' e 'obligationes', en Labeo, 20 (Napoli, 1974), pp. 104-125.

- Materiali per un corso di fondamenti del diritto europeo (Torino, Giappichelli, 2008), II.

Castresana Herrero, Amelia, Reflexión sobre la significación juridica de 'auctoritas', 'credere' y 'pontifex' a propósito de las etimologías de A. Pariente, en BIDR., 91 (Roma, 1988), pp. 419-445. 
—Derecho romano. El arte de lo bueno y de lo justo (Madrid, Tecnos, 2013).

Castro Sáenz, Alfonso, Responsabilidad y duplicidad formularia: los casos del depósito y el comodato en la época clásica, en Murillo, Alfonso (ed.), La responsabilidad civil: de Roma al derecho moderno (Burgos, Universidad de Burgos, 2001), pp. 187-208.

Cerami, Pietro; Petrucci, Aldo, Diritto commerciale romano. Profilo storico ${ }^{3}$ (Torino, Giappichelli, 2010).

CHerchi, Alice, Ricerche sulle 'usurae' convenzionali nel diritto romano classico (Napoli, Jovene, 2012).

Costa, Paolo, Pecunia constituta: ipotesi interpretative, en SDHI., 77 (Città del Vaticano, 2011), pp. 129-255.

D’Ors, Álvaro, Presupuestos críticos para el estudio del derecho romano (Salamanca, Colegio Trilingüe de la Universidad, 1943).

-Re et verbis, en Moschetтi, Guiscardo (ed.), Atti del Congresso Internazionale di Diritto Romano e di Storia del Diritto, Verona 27-28-29 IX 1948 (Milano, Giuffrè, 1951), III, pp. 265-303.

—Observaciones sobre el 'edictum de rebus creditis', en SDHI., 19 (Città del Vaticano, 1953), pp. 134-201.

-Creditum y contractus, en AHDE., 26 (Madrid, 1956), pp. 6-29.

-Creditum, en AHDE., 33 (Madrid, 1963), pp. 345-364.

-Recensión a Grosso, Giuseppe, Il sistema romani dei contratti (Torino, Giappichelli, 1963), en Iura, 15 (Napoli, 1964), pp. 390-397.

-Réplicas Panormitanas I. De nuevo sobre 'creditum' (Réplica a la crítica de Albanese), en SDHI., 41 (Città del Vaticano, 1975), pp. 205-244.

Ernout, Alfred; Meillet, Antoine, Dictionnaire Étymologique de la langue latine. Histoire des mots ${ }^{4}$ (Paris, Klincksieck, 1959).

Evans-Jones, Robin, The action of the XII Tables 'ex causa depositi', en Labeo, 34 (Napoli, 1988), pp. 188-208.

FALCONE, Giuseppe, Sistematiche gaiane e definizione di obligatio, en CAPOGROSSI-COLOGNESI, Luigi; CunsI, Maria Floriana (eds.), Obligatio-obbligazione. Un confronto interdisciplinare (Atti del Convegno di Roma 23-24 settembre 2010) (Napoli, Jovene, 2011), pp. 17-52.

FIORI, Roberto, La definizione della 'locatio conductio'. Giurisprudenza romana e tradizione romanistica (Napoli, Jovene, 1999).

Gandolfi, Giuseppe, Il deposito nella problematica della giurisprudenza romana (Milano, Giuffrè, 1976).

Giuffrè, Vincenzo, La 'datio mutui'. Prospettive romane e moderne (Napoli, Jovene, 1989).

Grosso, Giuseppe, Obbligazioni. Contenuto e requisiti della prestaz̧ione, obbligazioni alternative e generiche $e^{2}$ (Torino, Giappichelli, 1955).

GuZmán Brito, Alejandro, Los actos y contratos irregulares en el derecho chileno (Santiago, Ediciones Universidad Católica de Chile, 2016).

Heumann, Hermann Gottlieb; Seckel, Emil, Handlexikon zu den Quellen des römischen Rechts $^{9}$ (Jena, Fischer, 1926).

Jung, Byoung-Ho, Darlehensvalutierung im römischen Recht (Göttingen, Wallstein, 2002).

KASER, Max, Quanti ea res est. Studien zur Methode der Litisästimation im klassischen römischen Recht (München, C.H. Beck, 1935).

—Das Römische Privatrecht ${ }^{2}$ (München, C.H. Beck, 1971), I.

— Studien zum römischen Pfandrecht (Napoli, Jovene, 1982).

—; HackL, Karl, Das Römische Zivilprozessrecht2 (München, C.H. Beck, 1996). 
KLami, Hannu Tapani, 'Mutua magis videtur quam deposita'. Über die Geldverwabrung im Denken der römischen Juristen (Helsinki, Societas Scientiarum Fennica, 1969).

KranjC, Janez, In ius und in factum konzipierte Klageformel bei der Leihe und bei der Verwahrung, en ERnST, Wolfgang; JAKAB, Eva (eds.), Usus antiquus juris romani. Antikes Recht in lebenspraktischer Anwendung (Heidelberg, Springer-Verlag, 2005), pp. 127-161.

Lenel, Otto, Palingenesia Iuris Civilis (Leipzig, ex officina Bernhardi Tauchnitz, 1889), 2 vols.

—Das Edictum Perpetuum. Ein Versuch zu seiner Wiederherstellung ${ }^{3}$ (1883, Leipzig, Tauchnitz, 1927).

Litewski, Wieslaw, Le dépôt irrégulier (II), en RIDA., 22 (Liège, 1975), pp. 279-315.

-Depositary's liability in Roman Law, en AG., 190 (Modena, 1976), pp. 3-78.

Mantovani, Dario, Le formule del processo privato romano. Per la didattica delle Istituzioni di diritto romano ${ }^{2}$ (1992, Padova, CeDAM, 1999).

Martini, Remo, Due testi per la storia del c.d. 'credere' edittale, en Atti del II Seminario romanistico gardesano promosso dall' Istituto milanese di diritto romano e storia dei diritti antichi, 12-14 giugno 1978 (Milano, Giuffrè, 1980), pp. 109-121.

—Gaio e le res cottidianae, en AUPA., 55 (Palermo, 2012), pp. 171-188.

Maschi, Carlo Alberto, La categoria dei contratti reali. Corso di diritto romano (Milano, Giuffrè, 1973).

Metro, Antonino, Locazione e acquisto della proprietà: la c.d. locatio-conductio 'irregularis', en SCDR., 7 (Madrid, 1995), pp. 191-216.

Milazzo, Antonio, Il contratto di comodato. Modelli romani e disciplina moderna (Torino, Giappichelli, 2018).

Nelson, H.L.W.; Manthe, Ulrich, Gai Institutiones III 88-181. Die Kontraktsobligationen. Text und Kommentar (Berlin, Duncker \& Humblot, 1999).

Panero Gutiérrez, Ricardo, Deponere y reddere en la actio depositi in factum (Barcelona, Promociones y Publicaciones Universitarias, 1989).

—El depósito, en Paricio Serrano, Javier (ed.), Derecho romano de obligaciones. Homenaje al profesor José Luis Murga Gener (Madrid, Centro de Estudios Ramón Areces, 1994), pp. 251-281.

PARIENTE, Ángel, Sobre la etimología de 'credere', en SDHI., 19 (Città del Vaticano, 1953), pp. 340-342.

PASTORI, Franco, Concetto e struttura della obbligazione nel diritto romano (Milano, Cisalpino, 1985).

- Il commodato in diritto romano (Bologna, Cisalpino, 1995).

Pennitz, Martin, Das 'non reddere' als Deliktstatbestand-Juristendiskurse ₹u Besit₹, Detention und Diebstabl, en Index, 46 (Napoli, 2018), pp. 201-225.

Pernice, Alfred, Labeo. Römisches Privatrecht im ersten Jahrbundert der Kaiserzeit (Halle, 1873, reimp. Aalen, Scientia, 1963), 3 vols.

Perozzi, Silvio, Istituzioni di diritto romano ${ }^{2}$ (Roma, Athenaeum, 1928), 2 vols.

Petrucci, Aldo, Mensam exercere. Studi sullimpresa finanziaria romana (II secolo a.C. - metà del III secolo d.C.) (Napoli, Jovene, 1991).

-Profili giuridici delle attività e dell'organizzazione delle banche romane (Torino, Giappichelli, 2002).

PlatscheK, Johannes, Das Edikt de pecunia constituta. Die römische Erfüllungszusage und ihre Einbettung in den hellenistischen Kreditverkehr (München, C.H. Beck, 2013).

—Das Verbältnis der Institutiones zu den so genannten Res cottidianae sive aurea, en BABUSIAUX, 
Ulrike; Mantovani, Dario (eds.), Le Istituzioni di Gaio: avventure di un bestseller. Trasmissione, uso e trasformazione del testo (Pavia, Pavia University Press, 2020), pp. 279-302.

Provera, Giuseppe, Diritto e azione nell'esperienza giuridica romana, en Pastori, Franco (ed.), Studi in onore di Arnaldo Biscardi (Milano, Istituto Editoriale Cisalpino, 1983), IV, pp. 325-348.

Pulitanò, Francesca, De eo quod certo loco. Studi sul luogo convenzionale dell'adempimento nel diritto romano (Milano, Giuffrè, 2009).

Quadrato, Renato, Le Institutiones nell'insegnamento di Gaio. Omissioni e rinvii (Napoli, Jovene, 1979).

Rотн, Hans-Jörg, Alfeni Digesta. Eine spätrepublikanische Juristenscbrift (Berlin, Duncker \& Humblot, 1999).

Rotond, Giovanni, Leges publicae populi romani. Elenco cronologico con una introduzione sull'attività legislativa dei comizi romani (Milano, Società Editrice Libraria, 1912).

- Contributi alla storia del contratto di deposito nel diritto romano. Le due formule classiche dell'actio depositi, en Arangio-Ruiz, Vincenzo; Albertario, Emilio; De Francisci, Pietro (eds.), Scritti giuridici (Milano, Ulrico Hoepli, 1922), II, pp. 1-55.

- Contributi alla storia del contratto di deposito nel diritto romano. La misura della responsabilità nell'actio depositi, en Arangio-Ruiz, Vincenzo; Albertario, Emilio; De Francisci, Pietro (eds.), Scritti giuridici (Milano, Ulrico Hoepli, 1922), II, pp. 91-136.

RÜFNER, Thomas, Vertretbare Sachen? Die Geschichte der res, quae pondere numero mensura constant (Berlin, Duncker \& Humblot, 2000).

SACCoccio, Antonio, Si certum petetur. Dalla condictio dei veteres alle condictiones giustinianee (Milano, Giuffrè, 2002).

SAntoro, Raimondo, Studi sulla condictio, en AUPA., 32 (Palermo, 1971), pp. 181-512.

SAntucci, Gianni, Il principio dell'utilità dei contraenti, en Diritto romano e diritti europei. Continuità e discontinuità nelle figure giuridiche ${ }^{2}$ (Bologna, Il Mulino, 2018), pp 69-109.

SCHeIBelReIter, Philipp, Zwischen furtum und Litiskreszenz: Überlegungen zur poena dupli der actio ex causa depositi, en RIDA., 56 (Liège, 2009), pp. 131-154.

—Infitiando depositum nemo facit furtum? Zu den Ursprüngen der Verwahrerbaftung, en BuONgIorno, Pierangelo; Lohsse, Sebastian (eds.), Fontes Iuris. Atti del VI Jabrestreffen Junger Romanistinnen und Romanisten. Lecce, 30-31 marzo 2012 (Napoli, Edizioni Scientifiche Italiane, 2013), pp. 179-204.

Schulz, Fritz, Classical Roman Law (Oxford, Oxford University Press, 1951).

SolazzI, Siro, Il concorso dei creditori nel diritto romano (Napoli, Jovene, 1940), III.

TAFAro, Sebastiano, Regula e ius antiquum in D.50.17.23. Ricerche sulla responsabilità contrattuale (Bari, Cacucci, 1984).

Valmaña Ochaita, Alicia, El depósito irregular en la jurisprudencia romana (Madrid, Edisofer, 1996).

Varvaro, Mario, Per la storia del certum. Alle radici della categoria delle cose fungibili (Torino, Giappichelli, 2008).

- Sulla storia dell'editto de pecunia constituta, en Studi in onore di Remo Martini (Milano, Giuffrè, 2009), III, pp. 829-871.

Veronese, Benedetta, Buona fede e duplicità delle tutele processuali nei contratti di deposito e comodato, en Garofalo, Luigi (ed.), 'Actio in rem' e 'actio in personam'. In ricordo di Mario Talamanca (Padova, CedAm, 2011), II, pp. 239-278.

Walde, Alois; Hofmann, Johann Baptist, Lateinisches Etymologisches Wörterbuch ${ }^{3}$ (Heidelberg, Winter, 1938), 3 vols.

Walter, Tom, Die Funktionen der actio depositi (Berlin, Duncker \& Humblot, 2012). 
Wegmann Stockebrand, Adolfo, Obligatio re contracta. Ein Beitrag zur sogenannten Kategorie der Realverträge im römischen Recht (Tübingen, Mohr Siebeck, 2017).

-En torno al carácter (cuasi)contractual de la solutio indebiti en las Instituciones de Gayo, en REHJ., 39 (Valparaíso, 2017), pp. 85-110.

- Sobre el asi llamado contrato real en las Instituciones de Gayo, en REHJ., 40 (Valparaíso, 2018), pp. 97-122.

- Causae credendi y obligatio re contracta en las res cottidianae, en REHJ., 41 (Valparaíso, 2019), pp. 87-109.

— ¿Re obligamur, cum res ipsa intercedit? Sobre el asi llamado contrato real en Modestino, en RCbD., 46/3 (2019), pp. 669-689.

- ¿Ex causa depositi condicere? Observaciones sobre credere y deponere en el pensamiento de Paulo, en REHJ., 42 (Valparaíso, 2020), pp. 193-216.

WIEACKER, Franz, Römische Rechtsgeschichte (München, C.H. Beck, 1988), I.

Wycisk, Tonia, Quidquid in foro fieri potest - Studien zum römischen Recht bei Quintilian (Berlin, Duncker \& Humblot, 2008).

WubBe, Felix, Gaius et les contrats réels, en TR., 35 (Leiden, 1967), pp. 500-525.

-I contratti reali alla fine della repubblica, en Milazzo, Francesco (ed.), Contractus e pactum. Tipicità e libertà negoziale nell'esperienza tardo-repubblicana (Napoli, Edizioni Scientifiche Italiane, 1990), pp. 109-121. 